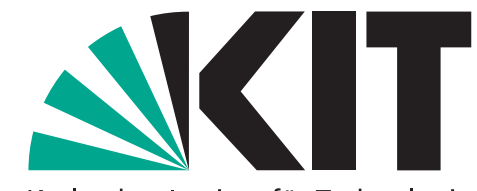

Karlsruher Institut für Technologie

\title{
Human frictions in the transmission of economic policy
}

by Francesco D’Acunto, Daniel Hoang, Maritta Paloviita and Michael Weber

No. 128 | JANUARY 2019

\section{WORKING PAPER SERIES IN ECONOMICS}

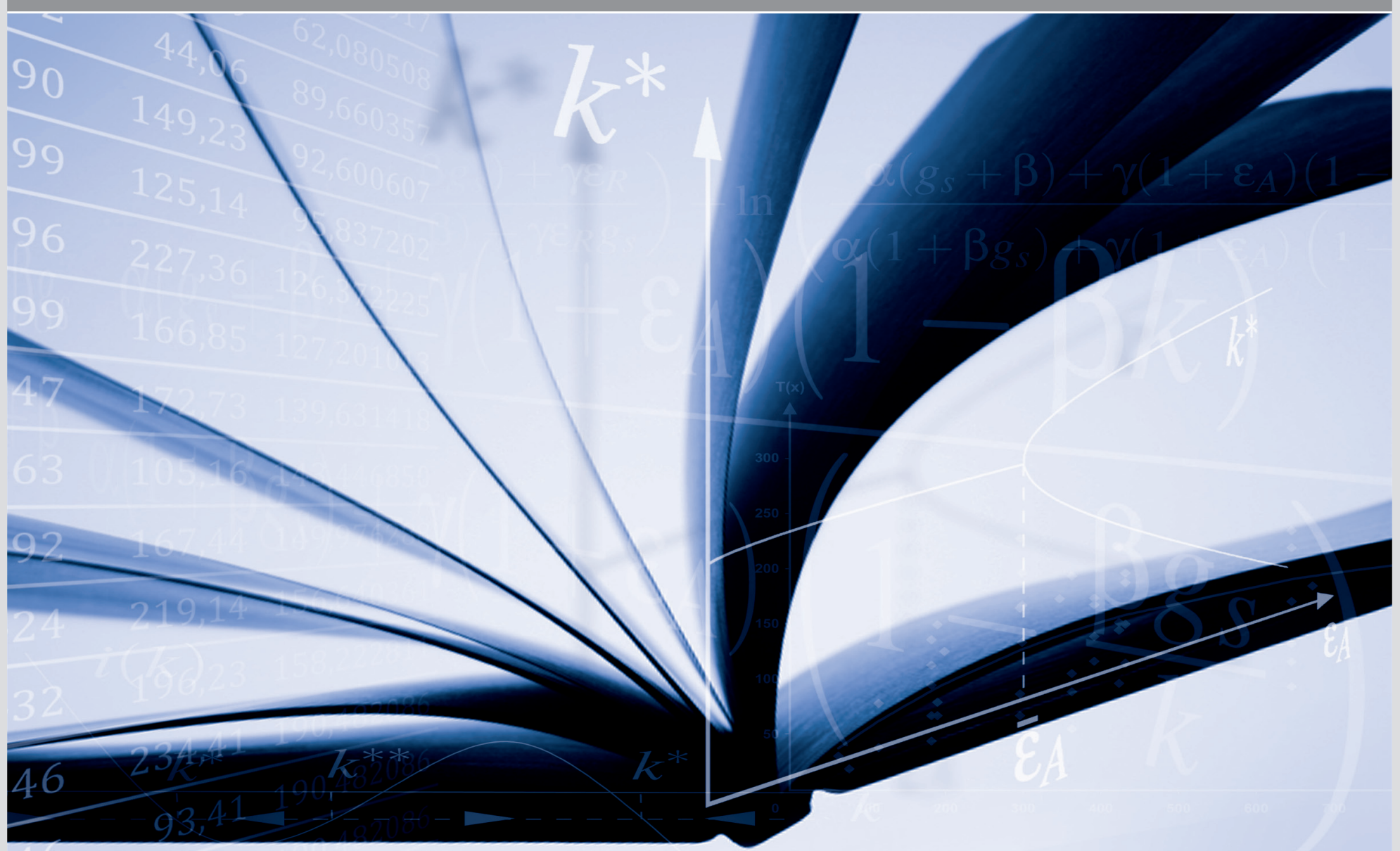




\section{Impressum}

Karlsruher Institut für Technologie (KIT)

Fakultät für Wirtschaftswissenschaften

Institut für Volkswirtschaftslehre (ECON)

Kaiserstraße 12

76131 Karlsruhe

KIT - Die Forschungsuniversität in der Helmholtz-Gemeinschaft

Working Paper Series in Economics

No. 128, January 2019

ISSN 2190-9806

econpapers.wiwi.kit.edu 


\title{
Human Frictions in the Transmission of Economic Policy*
}

\author{
Francesco D’Acunto, ${ }^{\dagger}$ Daniel Hoang, ${ }^{\ddagger}$ Maritta Paloviita, ${ }^{\S}$ and Michael Weber ${ }^{\llbracket}$
}

This version: January 2019

\begin{abstract}
Intertemporal substitution is at the heart of modern macroeconomics and finance as well as economic policymaking, but a large fraction of a representative population of men - those below the top of the distribution by cognitive abilities (IQ) - do not change their consumption propensities with their inflation expectations. LowIQ men are also less than half as sensitive to interest-rate changes when making borrowing decisions. Our microdata include unique administrative information on cognitive abilities, as well as economic expectations, consumption and borrowing plans, and total household debt from Finland. Heterogeneity in observables such as education, income, other expectations, and financial constraints do not drive these patterns. Costly information acquisition and the ability to form accurate forecasts are channels that cannot fully explain these results. Limited cognitive abilities could be human frictions in the transmission and effectiveness of fiscal and monetary policies that operate through household consumption and borrowing decisions.
\end{abstract}

JEL classification: D12, D84, D91, E21, E31, E32, E52, E65

\begin{abstract}
Keywords: Macroeconomic Beliefs, Limited Cognition, Heterogeneous Agents, Fiscal and Monetary Policy, Survey Data, Household Finance.
\end{abstract}

* This research was conducted with restricted access to data from the Finnish Defence Forces and Statistics Finland. The views expressed here are those of the authors and do not necessarily reflect the views of Finnish Defence Forces, Statistics Finland, the Bank of Finland, or the European Central Bank. We thank the project coordinator at Statistics Finland, Valtteri Valkonen, for his help with the data and very insightful comments. We also thank George-Marios Angeletos, Richard Blundell, Markus Brunnermeier, Bob Chirinko, Doug Diamond, Gene Fama, Nicola Gennaioli, Mark Gertler, Simon Gilchrist, Luigi Iovino, Lubos Pastor, Monika Piazzesi, Raghu Rajan, Andrei Shleifer, Gianluca Violante, Amir Yaron, and conference and seminar participants at Aalto University, the Bank of Finland, the Board of the Bank of Finland, CES-ifo Summer Institute: Expectation Formation, CES-ifo Workshop on Subjective Expectations and Probabilities in Economics, CEBRA Annual Meeting, CEPR Household Finance Conference, Danmarks Nationalbank, Cowles Macro Conference, the European Central Bank, the EABCN Asset Pricing and Macro Conference, European Midwest Micro/Macro Conference, Federal Reserve Board, Humboldt University, NBER Monetary Economics Meeting, UC Berkeley, Symposium on Economics and Institutions, University of Chicago, University of Mannheim, and WHU for valuable comments. We gratefully ackowledge finacial support from the Deutsche Bundesbank. Weber also gratefully acknowledges financial support from the University of Chicago Booth School of Business, the Cohen Keenoy Faculty Research Fund at the University of Chicago Booth School of Business, and the Fama-Miller Center.

${ }^{\dagger}$ Carroll School of Management, Boston College, Chestnut Hill, MA, USA. e-Mail: dacuntof@bc.edu

${ }^{\ddagger}$ Department for Finance and Banking, Karlsruhe Institute of Technology, Karlsruhe, B-W, Germany. e-Mail: daniel.hoang@kit.edu

$\S$ Bank of Finland, Helsinki, Finland. e-Mail: Maritta.Paloviita@bof.fi

TBooth School of Business, University of Chicago, Chicago, IL, USA and NBER. e-Mail: michael.weber@chicagobooth.edu. 


\section{Introduction}

In particular, low interest rates encourage households to bring forward durable consumption, and firms' investment, through credit.

Mario Draghi (2016)

The consumption Euler equation is at the heart of modern dynamic models in macroeconomics and finance. Conventional monetary policy aims to stabilize the economy by changing interest rates, and hence households' consumption expenditure through intertemporal substitution. Intertemporal substitution is also central to the effectiveness of unconventional monetary policy and conventional or unconventional fiscal policies. ${ }^{1}$ Standard models and policies assume agents form their expectations rationally and react to changes in expectations. Empirically, many policies that aim to manage households' expectations and hence choice are not as effective as representative-agent models imply, with forward guidance being a recent example (McKay, Nakamura, and Steinsson (2016)). ${ }^{2}$

In this paper, we argue that limited cognitive abilities are human frictions to the effectiveness of policies that operate through household expectations. In a representative sample of Finnish men for whom we observe administrative data on cognitive abilities through IQ tests, only men with high cognitive abilities adjust their consumption propensities in response to changes in inflation expectations. ${ }^{3}$ High-IQ men are also twice as sensitive to changes in interest rates when making borrowing decisions compared to low-IQ men, at times of both increases and decreases of policy rates. Differences in income, education, borrowing constraints, or other expectations such as household income expectations cannot explain the heterogeneity in consumption and borrowing responses by IQ.

Men with low cognitive abilities are economically relevant because they represent

\footnotetext{
${ }^{1}$ See Eggertsson and Woodford (2003), Farhi and Werning (2016), and Correia, Farhi, Nicolini, and Teles (2013).

${ }^{2}$ Earlier research found conflicting results on whether households' choice reacts to their inflation expectations. For instance, see Bachmann et al. (2015), Crump et al. (2018), and D'Acunto, Hoang, and Weber (2018a).

${ }^{3}$ In a companion paper (D'Acunto, Hoang, Paloviita, and Weber (2019)), we show the quality and consistency of economic expectations and economic choices that high-cognitive-ability men form is substantially higher than those of low-cognitive-ability men.
} 
more than $50 \%$ of the individuals and $50 \%$ of the income in our sample. Any non-response to policy changes by these men might be material to explaining the limited effectiveness of policy interventions implemented under the assumption that unconstrained households react.

We base our analysis on administrative individual-level data from Finland. Around age 20, Finnish men take a standardized test of cognitive abilities when entering the mandatory military service. We observe the scores of all test takers between 1982 and 2001, which are provided as a standardized variable that follows a stanine distribution (integers from 1 to 9 , with 9 being the highest) to allow cross-cohort comparisons. We match these test scores with the individual-level answers to the monthly harmonized European Commission Consumer Survey (EU survey) from 2001 to 2015. This survey elicits inflation expectations, propensities to consume and borrow, as well as a rich set of demographics such as age, education, marital status, income, household size, and employment status for a set of repeated representative cross sections of Finns. In addition, we observe total debt outstanding at the household level from tax records.

We build on these unique data and on the fact that cognitive abilities are an important determinant of macroeconomic expectations (see D'Acunto, Hoang, Paloviita, and Weber (2019)) to assess the relationship between cognitive abilities and individuals' responsiveness to economic policy. As a first step, we study whether individuals adjust their consumption plans in line with the consumption Euler equation. The EU survey asks how respondents think consumer prices will evolve in the following 12 months compared to the previous 12 months. ${ }^{4}$

We split the sample into high-IQ (scores of 6 to 9) and low-IQ (scores of 5 and below) respondents and find high-IQ respondents who think inflation will increase are almost $4 \%$ more likely relative to other high-IQ men to state it is a good time to spend. For low-IQ men, instead, we detect a negative and statistically insignificant association between inflation expectations and their readiness to spend. These results hold conditional on a rich set of demographics including education and income. Because low-IQ men do not react in line with the consumption Euler equation and account for a significant fraction of

\footnotetext{
${ }^{4}$ For ease of interpretation, we follow D'Acunto, Hoang, and Weber (2018a) and create a dummy variable that equals 1 when a household expects inflation to increase.
} 
overall income, these results suggest cognitive abilities could be a first-order impediment to the effectiveness of common fiscal and monetary policies that rely on intertemporal substitution.

One might worry low-IQ men are more likely to be financially constrained than highIQ men, which would explain the insensitivity of their consumption plans to changes in real interest rates (see Zeldes (1989)). Conditioning on household income does not affect any of our baseline results, and low-income households are plausibly more likely to be financially constrained than high-income households. We also confirm the baseline patterns when running our analysis separately for men above the median of the distribution by income, a subsample that includes both low- and high-IQ men.

Another potential concern is that expecting higher economic growth and hence higher income might deliver a spurious positive relationship between the propensity to spend and inflation expectations. We can rule out this concern directly, because we observe individual income expectations elicited at the same time as inflation expectations. We confirm our results when splitting the samples of high-IQ and low-IQ men into those men reporting positive or negative income expectations. These results suggest a subjective Phillips curve or indirect effects of monetary policy are unlikely to explain our findings (Kaplan, Moll, and Violante (2018)).

After documenting that men with low cognitive abilities do not behave in line with intertemporal substitution, we ask whether they react to changes in nominal interest rates, which are a cornerstone of conventional monetary policy. Central banks commonly lower nominal interest rates to stimulate consumption through household borrowing, and increase rates to avoid overheating, as the introductory quote by European Central Bank (ECB) President Draghi suggests. To tackle this question, we move on to test whether the relationship between individuals' propensity to borrow and changes in nominal interest rates varies systematically with individuals' cognitive abilities. ${ }^{5}$ An advantage of our setting is our sample period includes two significant policy interventions on nominal interest rates in opposite directions. The ECB, which has been responsible for the monetary policy of Finland since 1999, lowered its policy rate substantially during and

\footnotetext{
${ }^{5}$ Note we do not argue that reacting to changes in nominal interest rates is optimal for all households.
} 
Figure 1: ECB Deposit Facility Rate and Propensity to Borrow by IQ

Panel A. Borrowing: High-IQ Men

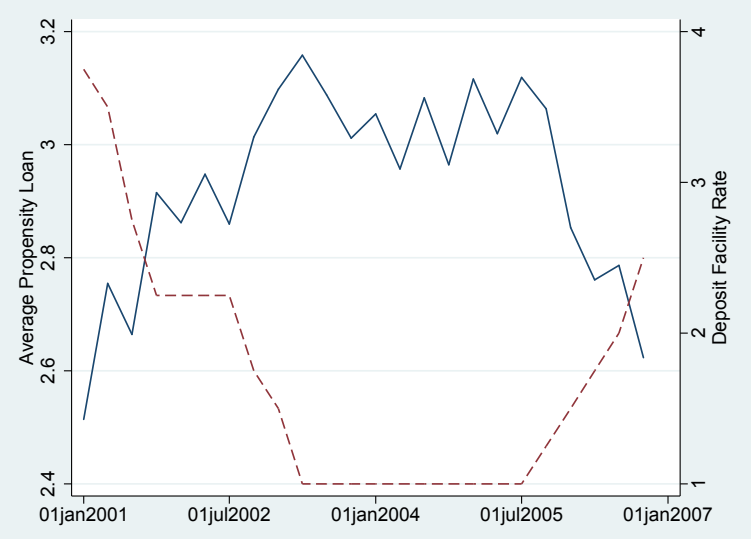

Panel B. Borrowing: Low-IQ

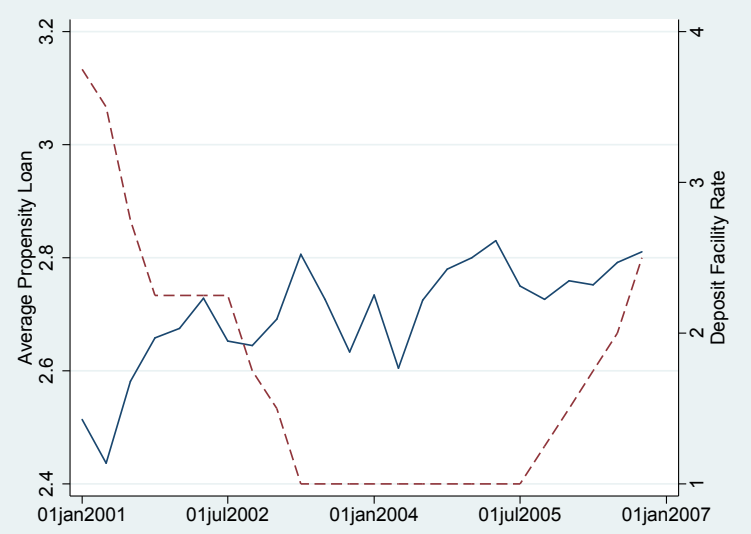

This figure plots the beginning of the quarter European Central Bank Deposit Facility Rate (red-dashed line) from quarter 1 2001 to quarter 4 of 2006. The solid-blue lines are the cross-sectional mean of whether individuals think it is a good time to take out a loan in Finland for high-IQ men in Panel A and for low-IQ men in Panel B. Individuals can answer that now is a "very good time to borrow" (4), a "pretty good time to borrow" (3), a "pretty bad time to borrow" (2), or a "really bad time to borrow" (1) to the question "If you think about the general economic situation in Finland, then do you think that at this time it is ..." High-IQ men are all men with the highest 3 scores of the 9-bin IQ distribution. Low-IQ men are all men with the lowest 3 scores of the 9-bin distribution. We use the confidential micro data underlying the official European Commission Consumer Survey to measure the propensity to take out a loan. IQ is the standardized test score from the Finnish Defence Forces. IQ obtains integer values between 1 and 9 with 9 being the highest score. The sample period is January 2001 to December 2006.

subsequent to the stockmarket turmoils of 2001. It kept rates low until 2005, and then increased rates steeply up to January 2007.

Effective transmission of these monetary-policy interventions requires that households increase their demand for loans when nominal rates drop, and decrease their demand for loans when nominal rates increase, ceteris paribus. High-IQ men behave in line with this predicted pattern, because their propensity to take out loans increases when rates fall, stays constant while interest rates do not move, and lowers when interest rates rise. To the contrary, low-IQ men appear to be less sensitive to changes in nominal interest rates when forming their borrowing plans, irrespective of the direction of the rate change. These results hold for the full sample as well if we limit the analysis to households that are unlikely to be financially constrained.

A differential pass-through of policy rates to individual borrowing rates for low- and high-IQ men might explain the differential borrowing sensitivities. A differential passthrough is an unlikely explanation because $95 \%$ of all mortages in Finland are adjustable- 
rate mortgages with a spread on the 12-month EURIBOR, and mortgages represented $74 \%$ of all consumer debt at the end of 2014. Alternatively, low-IQ men might be shut-off from financial markets, which is why they do not care about changes in interest rates. Using registry data, we find individual leverage ratios that are almost constant across the IQ distribution.

So far, we have exclusively studied the association between inflation expectations, interest rates, and survey decisions. Even though low-IQ men might not adjust their propensities to take out loans to changes in interest rates, it could still be the case highand low-IQ men might adjust their actual decisions in similar ways. Financial advisors, for example, might call low-IQ men and tell them now is a good time to take out a loan given interest rates are low. Using annual tax data, we find high-IQ men adjust their total outstanding debt balances significantly more to changes in interest rates than low-IQ men.

In the last part of the paper, we study a set of (non-mutually exclusive) channels that might explain our results to assess which interventions have a scope to counteract limited cognitive abilities in the transmission of economic policies and inform economic theory.

First, low-IQ men might be less informed about economic fundamentals like inflation than high-IQ men. We label this potential channel the costly information-gathering channel. The cognitive costs of gathering information about macroeconomic variables might be high for low-IQ men, who might thus behave rationally by deciding to not gather such information. We find that even the subset of low-IQ men that are correctly informed about inflation does not adjust consumption plans in response to changing inflation expectations.

The second channel we consider is that low-IQ men might have difficulties in thinking in probabilistic terms about future states of the world (McDowell and Jacobs (2017)). Under this costly expectations-formation channel, even well-informed low-IQ men might have miscalibrated expectations about macroeconomic variables, which might in turn explain their non-reaction to inflation expectations when forming consumption plans. Even low-IQ men who have accurate inflation expectations do not react to inflation expectations when forming consumption plans. This result suggests that the costly 
expectations-formation channel is unlikely to explain our results in full.

Because the tests for the first two channels do not provide us with a complete explanation of our results, we discuss a potential third channel - the lack-of-economic-reasoning channel. Even low-IQ men who have the relevant information about the current state of the economy as well as accurate expectations might still not understand basic economic concepts such as intertemporal substitution. This channel could also explain the excess sensitivity of consumption to predictable income changes (see, e.g., Parker et al. (2013)). The mechanism is consistent with Ilut and Valchev (2017), in which agents with limited cognitive abilities cannot map future states into optimal actions. Similarly, low-IQ men might not grasp the basic economic reasoning for why changing nominal interest rates might affect their incentives to borrow over time.

Low-IQ men represent $50 \%$ of the overall income held in our sample, and hence their inaction is material to the effective transmission of fiscal and monetary policy that operates through household decisions. At the same time, our findings would have relevant policy implications even if the fraction of income accruing to low-IQ men were smaller. In fact, an important implication of our results is a potential redistributive role of monetary policy. Because low-IQ men do not adjust their consumption plans in response to changes in their inflation expectations and to changes in interest rates, common monetary-policy interventions might result in redistribution from men with low cognitive abilities to men with high cognitive abilities. To the extent that cognitive abilities are largely innate or determined by environmental factors individuals can barely control in their early life, ${ }^{6}$ this redistribution might be interpreted as a form of unintended yet undue discrimination of economic agents on the part of policymakers.

\section{A. Related Literature}

Our paper also relates to the large literature that emphasizes the stabilization role of inflation expectations. On the monetary-policy side, Krugman et al. (1998), Eggertsson and Woodford (2003), Eggertsson (2006), and Werning (2012) argue that a central bank

\footnotetext{
${ }^{6}$ For a review of the scholarly debate on the origins of cognitive abilities see, among others, Mc-Gue et al. (1993) and Plomin and Spinath (2004).
} 
can stimulate current spending by committing to higher future inflation rates during periods in which the zero lower bound on nominal interest rates binds. On the fiscal policy side, Eggertsson (2011), Christiano, Eichenbaum, and Rebelo (2011), Woodford (2011), and Farhi and Werning (2016) show that inflation expectations can increase fiscal multipliers in standard New Keynesian models in times of a binding zero lower bound on nominal interest rates. We add to this literature showing that cognitive abilities determine whether individuals adjust their consumption plans in response to inflation expectations.

We also contribute to a recent literature that uses micro-level data to study the relationship between inflation expectations and households' readiness to purchase consumption goods. Bachmann et al. (2015) start this literature using survey data from the Michigan Survey of Consumers (MSC). They find an economically small and statistically insignificant association between households' inflation expectations and their readiness to spend on durable consumption goods. Burke and Ozdagli (2014) confirm these findings using panel survey data from the New York Fed/ RAND-American Life Panel household expectations survey for a period from April 2009 to November 2012. Ichiue and Nishiguchi (2015) find that Japanese households that expect higher inflation plan to decrease their future consumption spending, but have increased their spending in the past, whereas D'Acunto, Hoang, and Weber (2018a) and D'Acunto, Hoang, and Weber (2018b) show households on average behave in line with the predictions from the consumption Euler equation in EU countries. They also use a salient policy, namely the unexpected announcement of a future VAT increase, as a natural experiment to causally identify the effect. Arioli et al. (2017) confirm these findings for quantitative inflation expectations in Europe. Vellekoop and Wiederholt (2017) find the inflation expectations of Dutch households are systematically related to the composition of households' financial portfolios. Using data from the same survey, Christelis et al. (2016) find trust in the ECB lowers uncertainty about inflation expectations. Coibion, Gorodnichenko, and Kumar (2018) advance this literature using experimental variation to study causally the effect on inflation expectations on economic decisions. Malmendier and Nagel (2015) show that personal experiences determine inflation expectations. D'Acunto, Malmendier, Ospina, and Weber (2017) use unique survey data from the Nielsen homescan sample to 
show shopping experiences shape inflation expectations and determine the gender bias in inflation expectations.

Our findings stress the importance of cognitive abilities to shape individual economic decision-making. Papers that document the role of IQ in financial decision-making are Grinblatt, Keloharju, and Linnainmaa (2011), who study the effect on stock market participation, Grinblatt, Keloharju, and Linnainmaa (2012), who study the effect on trading behavior, and Grinblatt, Ikäheimo, Keloharju, and Knüpfer (2015), who study mutual fund choice. Agarwal and Mazumder (2013) relate cognitive abilities to suboptimal use of credit cards and home-equity loan applications. More recently, Aghion et al. (2017) use micro-level data on visiospatial IQ to study the effects of cognitive abilities, education, and parental income on inventiveness. Dal Bo, Finan, Folke, Persson, and Rickne (2017) relate IQ to the likelihood individuals enter political careers in Sweden. To the best of our knowledge, D'Acunto et al. (2019) is the first paper that shows cognitive abilities matter for the formation of economic expectations and choice. This paper is also the first one to interpret cognitive abilities as a potential human friction to the transmission of economic policy.

Increasing the transparency of economic policies and facilitating the public's understanding of policy targets are two key aims of the recent monetary-policy strategy in the United States. The heterogeneity of our findings across cognitive abilities, as well as the non-response of individuals with low cognitive abilities to policy changes, suggests some individuals might not fully understand the aims of policy changes and interventions. Cognitive abilities might therefore result in unintended consequences such as the redistribution of resources from individuals with low IQ to individuals with higher cognitive abilities, which calls for the design of salient policies and more targeted communication strategies (see D'Acunto et al. (2018a) and Coibion, Gorodnichenko, and Weber (2019)).

Our findings also inform the literature on the take-up of economic programs. In the Great Recession, the US administration initiated programs for underwater homeowners to refinance their mortgages, but the take-up rates were surprisingly low. Agarwal et al. (2017) study the effects and take-up rates of the 2009 Home Affordable Modification 
Program, which provided intermediaries with sizable financial incentives to renegotiate mortgages. They find a take-up rate of just one-third of the overall target population of indebted US households. Moreover, Keys et al. (2016) show 20\% of households that are unlikely to be constrained fail to refinance their mortgages when interest rates decline. Our findings suggest low cognitive abilities might help explain the limited effectiveness of these policies.

Our paper is also inspired by a recent literature on the forward guidance puzzle (see Del Negro, Giannoni, and Patterson (2015)) - the fact that forward guidance is not as effective empirically as representative-agent models imply. Deviations from the representative-agent framework could possibly explain the limited effectiveness. Borrowing constraints paired with uninsurable income shocks and asset holdings of different liquidity limit the scope of forward guidance and intertemporal substitution more generally (see McKay, Nakamura, and Steinsson (2016), Kaplan, Violante, and Weidner (2014), and Kaplan, Moll, and Violante (2018)). A recent theoretical literature explores deviations from rational expectations in this context. Farhi and Werning (2017) extend the standard New Keynesian model and allow for incomplete markets with uninsurable income shocks and bounded rationality in the form of level-k thinking. These two extensions can limit the power of monetary policy, especially at long horizons. Along similar lines, Woodford (2018) shows decision-makers that only optimize for a limited number of periods ahead can reduce the effectiveness of forward guidance. Gabaix (2018) develops a behavioral New Keynesian model in which a subset of agents is myopic, which mutes the power of forward guidance. Other recent theoretical models with level-k thinking are Garcia-Schmidt and Woodford (2019), who show that interest-rate commitments do not need to be deflationary in a liquidity trap, and Iovino and Sergeyev (2018)), who document that balance-sheet policies by central banks might be effective because of level-k thinking. We contribute to this literature by showing empirically that cognitive abilities help explain why large parts of the population might not adjust their consumption plans in response to inflation expectations and their borrowing propensities in response to changes in nominal interest rates. 


\section{Data}

Our analysis uses three micro data sets that include individual-level information on macroeconomic expectations, consumption and borrowing plans, and cognitive abilities, as well as administrative information on household-level income, debt, and interest rates.

\section{A. Expectations, Spending, and Borrowing Plans}

Our main source of information on individual-level macroeconomic expectations and consumption and borrowing propensities is the confidential micro data underlying the Consumer Climate Survey of Statistics Finland. Statistics Finland conducts the survey on behalf of the Directorate General for Economic and Financial Affairs of the European Commission as part of the European Commissions' harmonized consumer survey program. Every month, they ask a representative repeated cross section of approximately 1,500 Finnish individuals questions about general and personal economic conditions, inflation expectations, and willingness to spend on consumption goods. Statistics Finland also collects additional information through supplementary questions about households' plans to save and borrow.

The samples are drawn from the total population of 4.4 million individuals and 2.6 million households residing in Finland. The survey is run through phone interviews. In advance of the phone interview, Statistics Finland notifies all target individuals with a letter that contains information about the contents and logistics of the survey.

We obtained access to the micro data underlying the survey for the period starting in January 2001 and ending in March 2015. Our sample period includes large time variation in macroeconomic fundamentals as well as large variation policy rates of the ECB, which we exploit in the second part of our analysis.

We use the answers to the following three questions in the survey to construct the variables capturing spending plans and inflation expectations and perceptions:

Question 6 By comparison with the past 12 months, how do you expect that consumer prices will develop in the next 12 months? 
Individuals can answer, "Prices will increase more rapidly," "Prices will increase at the same rate," "Prices will increase at a slower rate," "Prices will stay about the same," or "Prices will fall." We create a dummy variable that equals 1 when households answered, "Prices will increase more rapidly," to get a measure of higher expected inflation. ${ }^{7}$

Households' inflation expectations are highly correlated with their perception of past inflation (see Jonung (1981)). We also use survey question 4 in our baseline analysis to disentangle the effects of inflation expectations from inflation perceptions:

Question 4 How do you think that consumer prices have developed over the last 12 months?

Individuals can answer, "Prices have risen a lot," "Prices have risen moderately," "Prices have risen slightly," "Prices have stayed about the same," or "Prices have fallen." 8

To study the association between inflation expectations and spending propensities, we use the answer to the following question:

Question 10 In view of the general economic situation in Finland, do you think that now it is the right moment for people to make major purchases such as furniture, electrical/ electronic devices, etc.?

Households can answer, "It is neither the right moment nor the wrong moment," "No, it is not the right moment now," or "Yes, it is the right moment now."9

We use the answers to the following question to study the propensity to take out loans in response to changes in nominal intererst rates:

Question 22 In view of the general economic situation in Finland, do you think that at the moment ...

Households can answer, "It is a very bad time to borrow," "It is a pretty bad time to borrow," "It is a pretty good time to borrow," or "It is a very good time to borrow." 10

\footnotetext{
${ }^{7}$ The question corresponds to question 6 in the harmonized EC survey.

${ }^{8}$ The question corresponds to question 5 in the harmonized EC survey.

${ }^{9}$ The question corresponds to question 8 in the harmonized EC survey.

${ }^{10}$ The question is not part of the harmonized EC survey.
} 
In addition, we use questions regarding expectations about general macroeconomic variables, personal income, and a rich set of socio-demographics from the Statistics Finland survey, which include gender, age, marital status, household size, income, employment status, number of children, region of residence, and education levels.

\section{B. Cognitive Abilities Data}

Finland has general conscription for men, which means that all Finnish men between the ages of 18 and 60 are liable for military or non-military service. The share of men who do non-military service is only about $3 \%$ of all men who start military service. ${ }^{11}$ Within the first weeks of the mandatory military service, Finnish men typically around the age of 19-20 have to participate in a series of tests. The FDF administers these tests and uses the results to select candidates for possible officer training. Because ranking well in the IQ test provides a set of advantages in terms of quality of training and access to elite social networks, men have an incentive to perform as well as possible on the test (Grinblatt et al. (2011)).

The test consists of 120 questions that attempt to test cognitive abilities in three areas - visuospatial, mathematical, and verbal cognitive abilities. The FAF aggregates those scores into a composite measure of cognitive abilities, which we label collectively as IQ. The FAF standardizes IQ to follow a stanine distribution year by year. Stanine (STAndard NINE) is a method of scaling test scores on a 9-point standard scale with a mean of 5 and a standard deviation of 2 . The respondents in the lowest $4 \%$ of test scores are at least 1.75 standard deviations from the mean and are assigned a standardized IQ of 1 and the $4 \%$ with the highest test scores are assigned a standardized IQ of 9 . We have test results for all participants from January 1, 1982 until December 31, 2001.

Finland is a homogeneous country in terms of cultural background and opportunities. Access to education, including college education, is virtually for free. The country is also racially homogeneous (Grinblatt et al. (2011)). These features make the Finnish setting a desirable laboratory because our measures of IQ are unlikely to proxy for differences in cultural or environmental factors individuals could manipulate, but are more likely to

\footnotetext{
${ }^{11}$ Please see https://puolustusvoimat.fi/en/conscription for these and additional details.
} 
reflect differences in innate abilities across individuals.

\section{Income and Debt Data from Registries}

We also have access to administrative income and debt data for all Finnish full-time residents at the end of each calendar year through Statistics Finland. The data contain information on individuals' labor and business incomes, received and paid income transfers, as well as overall household liabilities. The information is collected from underlying sources across various agencies (Tax Administration, National Institute for Health and Welfare, Statistics Finland, Kela), administrative registers, and statistical repositories.

\section{Descriptive Statistics}

Table 1 contains the descriptive statistics for the main variables in our analysis. The median income is EUR 21,000 and the median respondent is 30 years old. $61 \%$ of respondents are single, $6 \%$ are unemployed, $78 \%$ have children, $34 \%$ have a college degree, about a third lives in urban areas, and 28\% live in Helsinki. 51\% of respondents think it is a good time to buy durables, $20 \%$ think it is a bad time, and the other respondents think it is neither a good nor a bad time.

Table 2 reports the distribution of normalized IQ in Panel A, the average household leverage ratio by IQ bins in Panel B, and the share of income in total income that accrues to the individual IQ bins in Panel C. Panel B shows little variation in household leverage ratios by IQ. Specifically, low-IQ men have a ratio of total debt to taxable income of $82 \%$, which is slightly higher than the ratio for all bins up to a normalized IQ of 7 . High-IQ men, instead, have a minimally higher leverage ratio of 0.93 . In the bottom panel, we see the share of income that accrues to the individual bins. Later in our empirical analysis, we will often split the sample into low and high IQ, with the latter defined as having a normalized IQ of 6 or higher. Note this implies low-IQ men make up $49.2 \%$ of total income and are therefore a large share of aggregate income in the economy.

D'Acunto et al. (2019) show the measure of cognitive abilities has a correlation 
of only 0.15 with income and that IQ and forecast errors for inflation are negatively correlated. Variation in observables such as income or education does not drive the correlation between IQ and inflation expectations.

\section{Inflation Expectations, IQ, and Consumption Expenditure}

Most existing models studying fiscal and monetary policies assume a representative agent that has all available information, forms expectations rationally, and fully optimizes. The consumption Euler equation is at the core of all modern dynamic models in macro and finance and predicts a positive association between consumption plans and inflation expectations. This association means if the agent expects higher inflation, he should substitute intertemporally and consume more now rather than later. In the textbook New Keynesian model, monetary policy affects real outcomes purely through this intertemporal substitution channel. Moreover, unconventional monetary-policy measures, such as forward guidance, as well as unconventional fiscal policies also aim to increase households' inflation expectations and stimulate consumption through intertemporal substitution (see Kaplan et al. (2018) and D'Acunto et al. (2018a)). Hence, several types of policies rely on intertemporal substitution.

Our baseline analysis focuses on this key building block - the consumption Euler equation - that is instrumental to testing whether limited cognitive abilities hinder the transmission of economic policies. The debate on whether individuals update their consumption plans with their inflation expectations is still ongoing. Bachmann et al. (2015) start this literature using microdata from the Michigan Survey of Consumers and find no association between consumption plans and inflation expectations, whereas Crump et al. (2018) find a positive association using data from the New York Fed Survey of Consumers.

We aim to test whether low-IQ and high-IQ men differ in the extent to which they update their consumption plans to changing inflation expectations. A crucial question is whether such differences underline any heterogeneity in consumption responses to 
changing inflation expectations. This step is necessary for cognitive abilities to have a role in individuals' responsiveness to economic and monetary-policy interventions based on intertemporal substitution.

\section{A. Empirical Model}

A common concern with survey-based measures of numerical inflation expectations is that households often report implausibly high levels of expected inflation. Moreover, many individuals report expected inflation rates as multiples of 5 or other round values, and a general upward bias exists (see, e.g., Binder (2015) and D'Acunto et al. (2019)).

To avoid all the issues arising when using numerical inflation forecasts (see D'Acunto, Hoang, and Weber (2018a) for a detailed discussion), we construct a dummy variable that equals 1 if the respondent expects a higher inflation rate in the following 12 months, compared to the prevailing inflation rate over the past 12 months, and zero otherwise. D'Acunto, Hoang, and Weber (2018a) show this measure tracks closely ex-post realized inflation across several samples in different countries and different time periods. A rationale for why this qualitative measure might track ex-post realized inflation more closely than quantitative measures is that respondents might have a clear idea of the directional changes in inflation they perceive and expect, but might be uninformed about the level of inflation prevailing at the time they are interviewed.

Our first outcome variable of interest, households' readiness to purchase durable goods, derives from discrete, non-ordered choices in a survey. We therefore model the response probabilities in a multinomial-logit setting.

We assume the answer to the question on the readiness to spend is a random variable representing the underlying population. The random variable may take three values, $y \in\{0,1,2\}: 0$ denotes it is neither a good nor a bad time to purchase durable goods, 1 denotes it is a bad time to purchase durable goods, and 2 denotes it is a good time to purchase durable goods.

We define the response probabilities as $P(y=t \mid X)$, where $t=0,1,2$, and $X$ is an $N \times K$ vector where $N$ is the number of survey participants. The first element of $X$ is a unit vector, and the other $K-1$ columns represent a rich set of household-level 
observables, including demographics and expectations.

We assume the distribution of the response probabilities is

$$
P(y=t \mid X)=\frac{e^{X \beta_{t}}}{1+\sum_{z=1,2} e^{X \beta_{z}}}
$$

for $t=1,2$, and $\beta_{t}$ is a $K \times 1$ vector of coefficients. The response probability for the case $y=0$ is determined, because the three probabilities must sum to unity.

We estimate the model via maximum likelihood to obtain the vector $\beta_{t}$ of coefficients for $t=1,2$, and set the category $y=0$ as the baseline response. We compute the marginal effects of changes in the covariates on the probability that households choose any of three answers in the survey, and report them in the tables.

\section{B. Empirical Results: Baseline}

Given the ongoing debate on the association between consumption plans and inflation expectations (Bachmann et al. (2015), Crump et al. (2018)), we first estimate the relationship between inflation expectations and readiness to purchase durable goods in the overall EU survey sample of men and women.

If the Euler-equation logic holds, we should observe a positive association between individuals' inflation expectations and their readiness to purchase durable goods. Table 3 reports the average marginal effects computed from the multinomial logit regressions of whether it is a good time to purchase durable goods on the dummy that equals 1 if the respondent thinks inflation will be higher in the following 12 months than it was in the previous 12 months. We cluster standard errors at the quarter level to allow for correlation of unknown form in the residuals across contiguous months. We always condition on perceptions of past inflation because they shape households' expectations about future inflation (Jonung (1981)). ${ }^{12}$ We see in column (1) that individuals who expect inflation to increase are on average $2.1 \%$ more likely to answer it is a good time to buy durables compared to individuals who expect constant or decreasing inflation.

Of course, large differences exist in households' purchasing propensities, which vary

\footnotetext{
${ }^{12}$ All results are qualitatively and quantitatively similar without conditioning on past inflation.
} 
systematically by demographic characteristics (see, e.g., Attanasio and Weber (1993)). Household and individual characteristics that determine both purchasing propensities and inflation expectations might be systematically related, and hence controlling for the observed heterogeneity across individuals is important to verify the association we document is not spurious. In column (2) of Table 3, we add a rich set of demographics including age, age $^{2}$, a dummy that equals 1 if the respondent is single and 0 otherwise, log of income, a dummy that equals 1 if the respondent has a college degree and 0 otherwise, an unemployment dummy, a dummy that equals 1 if the respondent has at least one child and 0 otherwise, a dummy that equals 1 if the respondent lives in a urban area and 0 otherwise, and a dummy that equals 1 if the respondent lives in Helsinki and 0 otherwise. The baseline positive association between inflation expectations and readiness to purchase durable goods is largely unchanged.

Having established that the baseline association between inflation expectations and readiness to consume is positive for the average individual in the full sample of men and women as the consumption Euler equation predicts, we move on to consider the subset of male respondents for whom we observe cognitive abilities. This subsample amounts to about $17 \%$ of the overall sample. When we repeat the specification of column (2) within this restricted subsample, we find a positive marginal effect of inflation expectations on consumption propensities, though is not statistically significant.

We find different results across sample splits on the association between inflation expectations and purchasing plans, which is reminiscent of the conflicting evidence for the US which we discussed above. But the nonresult on the association between inflation expectations and purchasing propensities we observe for the subsample of men might camouflage large heterogeneity on how different individuals respond in their consumption plans to inflation expectations. For instance, low-cognitive-ability men might not understand they should increase consumption when expecting higher inflation, ceteris paribus.

To understand whether cognitive abilities might be relevant to explaining if individuals' consumption propensities react to changes in inflation expectations, we split the whole sample into men with an IQ above 5 and other men. In columns (4) and (5) 
of Table 3, we repeat the analysis of column (3) separately for each of the two groups. Column (4) shows that in the subsample with high cognitive abilities, men are $3.6 \%$ more likely than other men with high IQ to say it is a good time to purchase durables when they expect inflation to increase. This result is consistent with the conjecture that high-IQ men understand intertemporal substitution as well as the consumption-Euler-equation logic, and hence their consumption plans react to inflation expectations.

When we move on to consider men with lower IQs (column (5)), we do find a negative but statistically insignificant marginal effect of inflation expectations on consumption propensities. Note that a statistical-power issue can barely explain this lack of reaction of the consumption plans of low-IQ men to inflation expectations, because the size of the samples in column (4) and column (5) are almost identical.

Overall, the results in Table 3 suggest that men with high cognitive abilities, but not other men, adjust their consumption plans in response to inflation expectations in line with the consumption Euler equation.

\section{Financial Constraints and Individual-level Shocks}

Binding financial constraints are a compelling alternative interpretation of our results. If low-IQ men are systematically more likely to be financially constrained than high-IQ men, low-IQ men's consumption plans might be insensitive to inflation expectations not because they do not understand intertemporal substitution, but because they cannot easily substitute their consumption expenditure intertemporally. To assess the relevance of this alternative interpretation, we repeat our baseline analysis, limiting the sample to respondents who are unlikely to be financially constrained. To proxy for the lack of financial constraints, we consider subsamples of respondents whose income is in the upper part of the income distribution.

Table 4 reports the marginal effects of expecting higher inflation on the willingness to purchase durable goods for respondents whose income is above the median income of men with IQ data (columns (2) and (3)) and whose income is above the $25^{\text {th }}$ percentile (columns (4) and (5)). In both cases, we replicate the baseline positive association between inflation expectations and readiness to spend on durable goods for high-IQ men. To the 
contrary, the consumption plans of low-IQ men appear to be insensitive to changes in inflation expectations even for those men who are unlikely to be financially constrained.

Another relevant concern is that income expectations might explain our baseline results, which could happen for several reasons. First, low-IQ men might have more negative expectations regarding other dimensions of their future personal outlook and/ -or macroeconomic variables, which might mute their willingness to adjust future consumption plans in response to inflation expectations (Das, Kuhnen, and Nagel (2018)). For instance, low-IQ men who expect higher inflation might also be more likely than high-IQ men to expect a job loss over the following 12 months. In this case, a negative expected income shock might counteract the effect of higher inflation expectations on consumption plans. Second, high-IQ men might adjust their consumption plans according to their inflation expectations not because they have a Euler equation in mind, but because they also expect higher income following an individual Phillips-curve logic. Third, Kaplan et al. (2018) show in heterogeneous-agent models with uninsurable income shocks and assets of different liquidity that conventional monetary policy affects consumption decisions mainly through changes in income, because of indirect effects on labor demand.

To assess the relevance of these channels different from intertemporal substitution, we exploit the richness of our expectations data. The survey asks about individuals' expectations regarding any changes in their income over the following 12 months, which should capture any potential household-level or macro-level shocks that are likely to produce income effects at the household level.

Table 5 replicates our baseline analysis using individual income expectations. In columns (2)-(3) of Table 5, we focus only on respondents who expect their income to increase over the following 12 months. Within this group, the consumption plans of high-IQ men react to inflation expectations, whereas the consumption plans of low-IQ men are insensitive to inflation expectations - if anything, the statistically insignificant association is negative. This result is direct evidence that even low-IQ men who do not expect any negative income shocks during the following 12 months do not adjust their consumption plans in response to inflation expectations. In columns (4)-(5) of Table 5, we move on to consider only respondents who expect their household income to stay the 
same or decrease over the following 12 months. Again, we detect the same patterns as in the baseline analysis, whereby high-IQ men adjust their consumption plans in response to inflation expectations, whereas the consumption plans of low-IQ men are insensitive to inflation expectations.

The results for high-IQ men suggest the consumer Euler equation plausibly explains our baseline results, whereas income effects based on a Phillips-curve logic or indirect effects of monetary policy are an unlikely explanation. Indirect effects of monetary policy in a heterogeneous-agent framework could still stimulate future consumption expenditure through higher realized labor income even for low-IQ men, but this policy could not be used as a tool to increase aggregate demand in the short run.

\section{Interest-Rate Transmission to Loans}

Low-IQ men do not seem to adjust their consumption plans in response to inflation expectations, which makes it unlikely that policies that purely rely on generating inflation expectations reach this part of the population and can directly stimulate households' current consumption (Coibion, Gorodnichenko, and Weber (2019)).

Another channel through which policy could affect individual behavior is a bank-lending channel; as the introductory quote by president Draghi highlights, conventional monetary policy uses short-term interest rates in an attempt to stabilize household consumption and investment in durable goods. We now study the propensity to take out loans over time - which we observe in the EU survey - in response to changes in nominal interest rates by cognitive abilities as well as total changes in household debt over time using administrative data.

The time period our survey covers includes a full cycle of decrease and increase in short-term nominal interest rates by the ECB from 2001 until 2006. Central banks often lower nominal interest rates during crises to stimulate consumption through loans. At the same time, central banks might increase nominal interest rates at times of sustained growth and inflationary pressure to avoid overheating, again through lower credit. 
Panel A of Figure 2 shows the cycle in ECB policy rates we consider. ${ }^{13}$ On May 31, 2001, the ECB lowered its deposit facility rate from $3.75 \%$ to $3.50 \%$ (right y-axis) and continued lowering the rate until it reached a trough of $1.00 \%$ on June 30, 2003. Recessionary pressure in France and Germany mainly drove the cuts in nominal rates. In times of low interest rates, financing conditions become more favorable and individuals have an incentive to borrow more. In our setting, we can control directly for individual expectations regarding future income and employment status, which absorbs the effects of potentially concurrent recessionary pressures on Finnish households' willingness to borrow. Panel A of Figure 2 further documents that the ECB kept the deposit facility rate stable from June 30, 2003, until June 30, 2005, when the ECB started to tighten monetary policy and increased rates throughout 2006 .

We first focus on survey responses, which allow us to study the demand-side for credit and to abstract from possible financial constraints. The question reads, "If you think about the general economic situation in Finland, then do you think that at this time it is ..." and individuals can answer that now is a "very good time to borrow" (4), a "pretty good time to borrow" (3), a "pretty bad time to borrow" (2), or a "really bad time to borrow" (1). Below, we will also directly study actual changes in household debt over time, which could be influenced by changes in credit supply and financial constraints.

Comparing Panels B and C of Figure 2, we see that the average propensity to take out loans is about 2.5 for both groups of men at the beginning of the period. During the period 2001-2003, while the ECB decreases short-term rates, high-IQ men increase their propensity to borrow, with a peak at 3.1 exactly when the facility rate reaches its lowest point for the 6-year period we consider. During the same period, low-IQ men's propensity to borrow increases only slightly, peaking at 2.8 in January 2003. Overall, the increase in the propensity of high-IQ men to borrow (0.6) is $100 \%$ higher than the increase in the propensity of low-IQ men to take out loans (0.3).

Men with low cognitive abilities might not increase their propensity to borrow, because of financial constraints instead of a lack of forward-looking behavior. The wording of the question makes it unlikely financial constraints explain the lower responsiveness of

\footnotetext{
${ }^{13}$ The figure plots the beginning of the quarter deposit facility rate. Other short-term policy rates such as the rate on the main refinancing operations move in parallel to the deposit facility rate.
} 
low-IQ men. The increase in the deposit facility rate starting on June 30, 2005, allows us to rule out directly financial constraints, because financial constraints can only limit the uptake of credit but not the reduction of credit following an increase in rates.

We see in Panel $\mathrm{C}$ of Figure 2 that high-IQ men reduce their propensity to borrow from 3.1 at the end of June 2005 to 2.6 in the third quarter of 2006. By contrast, low-IQ men do not change their propensity to borrow over the same period, despite the higher nominal interest rates.

These results point to a difference in the sensitivity of the propensity to borrow to changes in nominal interest rates across men with different levels of cognitive abilities. High-IQ men react to changes in nominal interest rates more than low-IQ men. Measures of monetary policy aimed at affecting the real economy through household borrowing might thus be less effective than representative-agent models predict, because a significant fraction of individuals - those with lower cognitive abilities - might not react to changing rates.

Our results so far did not absorb systematic heterogeneity across low-IQ and high-IQ men other than cognitive abilities nor assess the statistical significance of the differences in the reaction to changing nominal interest rates. We thus perform the analysis in a multivariate setting. We report the marginal effects for estimating specifications of the following type:

$$
\operatorname{Loan}_{i, t}=\alpha+\beta I Q_{i, t} \times \text { Post }_{t}+\gamma \text { Post }_{t}+\zeta I Q_{i, t}+X_{i . t}^{\prime} \delta+\eta_{t}+\epsilon_{i, t}
$$

where $\operatorname{Loan}_{i, t}$ is a dummy variable that equals 1 if respondent $i$ in month $t$ says it was a very good or pretty good time to take out a loan, and zero otherwise; $I Q_{i, t}$ is a dummy variable that equals 1 when the standardized IQ score of individual $i$ is 6 or above; Post $t_{t}$ is a dummy variable that equals 1 in the months after the ECB decreased or increased the facility rate, and zero in the months before the changes; and $X$ is a vector of individual level controls from above. We estimate this specification with a linear probability model (OLS) as well as using non-linear estimators.

Panel A of Table 6 reports the results for estimating equation (2) for the period of 
January 2001 to June 2003, during which the ECB cut the deposit facility rate. The Post dummy takes on the value of 1 starting in June 2001. Whether we study the raw data across all estimation methods (columns (1)-(3)) or absorb demographic characteristics (columns (4)-(6)), we find that (i) on average, all respondents are more likely to think it is a good time to borrow after the cut in interest rates, but (ii) the propensity to borrow increases significantly more for high-IQ men than for low-IQ men. High-IQ men increase their propensity to take out loans by $100 \%$ and up to $150 \%$ more than low-IQ men, as can be seen by comparing the estimated coefficients $\hat{\beta}$ to the estimated coefficients $\hat{\gamma}$ across all specifications.

Panel B of Table 6 reports the results for estimating equation (2) for the period July 2003 to December 2006, during which the ECB increased the facility rate. In this test, the Post dummy takes on the value of 1 starting in January 2006. Consistent with the conjecture that high-IQ men react more to changes in policy rates, the estimated coefficients $\hat{\beta}$ are negative and statistically different from zero; that is, high-IQ men are less likely than low-IQ men to claim it is a good time to take out a loan once nominal interest rates increase. Once we control for demographic heterogeneity, high-IQ men are about 3 times less likely to claim it is a good time to take out a loan compared to low-IQ men and compared to the period before the interest-rate increase.

The differential sensitivity in the propensity to take out loans to changes in nominal interest rates for men with high and low cognitive abilities both when interest rates decrease and when interest rates increase makes financial constraints an unlikely driver of these results.

Another explanation could be low-IQ men might be shut off from financial markets and not care about changes in interest rates. But Panel B of Table 2 shows total debt to taxable income is almost constant across the IQ distribution. Note also the survey question asks respondents whether it is a good time to take out a loan in general, and not whether it is a good time for their own households. Nevertheless, in the Online Appendix, we address these concerns directly by estimating equation (2) separately for men in the top fraction of the distribution by income, which includes households that are less likely to face financial constraints. The results of this robustness test, which we report in Table 
A.1 of the Online Appendix, corroborate the view that differences in the reaction to policy changes across levels of cognitive abilities might be driven by a different ability to understand economic incentives between high-IQ men and low-IQ men.

Moreover, a differential pass-through of policy rates to individual borrowing rates for low- and high-IQ men might explain our findings. For example, banks might systematically change interest rates more slowly for men with low cognitive abilities than for men with high cognitive abilities in response to changes in policy rates. This differential pass-through is an unlikely explanation because $95 \%$ of all mortgages in Finland are adjustable-rate mortgages with a spread on the 12-month EURIBOR, and mortgages represented $74 \%$ of all consumer debt at the end of 2014 .

Finally, so far we have studied exclusively the association between inflation expectations, interest rates, and survey decisions. Even though low-IQ men might not adjust their propensities to take out loans to changes in interest rates, it could still be the case high- and low-IQ men might adjust their actual decisions in similar ways for several reasons: (i) they might learn from family, neighbours, co-workers, or friends; (ii) supply-side forces might tell low-IQ men to adjust their decisions; for example, mortgage bankers might call these men and tell them now is a good time to take out loans given rates are low; (iii) they might be aware of their inability to optimize and rely on advice in general.

One drawback of using observational data is that those do not only capture individuals' propensity to borrow but also any unobservable dimension that drives their actual ability to borrow, such as credit constraints.

To test whether we observe differences in the behavior between low- and high-IQ men also in actual choices, we use registry data from Statistics Finland. We observe for each individual at an annual frequency the amount of total debt outstanding for tax purposes. We then calculate the annual change in total debt and regress it on the change in the deposit facility rate, estimating the following specification:

$$
\Delta \operatorname{Debt}_{i, t}=\alpha+\beta I Q_{i, t} \times \Delta \text { Rates }_{t}+\zeta I Q_{i, t}+X_{i . t}^{\prime} \delta+\eta_{t}+\epsilon_{i, t}
$$


where $\Delta D e b t_{i, t}$ is the annual change in total debt of respondent $i ; \Delta$ Rates $_{t}$ is the annual change in the ECB deposit facility rate; $I Q_{i, t}$ is a dummy variable that equals 1 when the standardized IQ score of individual $i$ is 6 or above; and $X$ is a vector of individual level controls. The sample period is 2001 to 2011 when the deposit facility rate reaches the effective lower bound.

Columns (1) and (2) of table 7 report the results for the sample from 2001 until 2011 when the change in the deposit facility rate reached 0 . We see the estimate for the interaction term is negative and marginally statistically significant when we average out demographic controls. An increase in the deposit facility rate of $1 \%$ reduces the amount of total debt by 57 Euros more for high-IQ men, which is about $3 \%$ of the average change during our sample.

Of course, the recent Great Recession and European Sovereign Debt Crisis are major macroeconomic events during this sample period and might affect the changes in debt. Columns (3) and (4) report results for a sample ending in 2007. Again, we see high-IQ men reduce their total debt more than low-IQ men. The estimate in column (4) when we partial out demographics equals around $4 \%$ of the average change in our sample.

Overall, irrespective of studying survey responses or actual borrowing decisions, we find high-IQ men are more responsive than low-IQ men to changes in nominal interest rates.

\section{Channels}

In the previous sections, we provided arguments for why channels such as households' financial constraints or expectations about future economic conditions are unlikely to explain our findings. In this section, we further investigate a set of channels that could help explain why low-IQ men might be less responsive than high-IQ men to inflation expectations.

First, low-IQ men might be less informed than high-IQ men about economic fundamentals including the current state, potentially because gathering information about macroeconomic variables is more cognitively costly to them (costly information-gathering 
channel). Therefore, low-IQ men could have miscalibrated perceptions about current inflation resulting in miscalibrated beliefs about future macroeconomic variables. As long as low-IQ men understand their expectations are biased, they would not rely on them when forming purchasing plans. D'Acunto et al. (2019) provide evidence consistent with the costly information-gathering channel.

To assess this channel directly, we exploit the fact that the survey asks households directly about their perception of the current 12-month inflation rate. Based on this question, we compute an inflation-perception error at the individual level as the difference between the perceived inflation rate and the prevailing inflation rate.

We focus on a sample of men with perception errors below the median within each month. These men represent individuals who are likely to be informed about the prevailing inflation rate at the time of the interview, and due to the large sample size, they are unlikely to be individuals who merely guessed the prevailing inflation rates while providing values at random.

In column (1) of Table 8, we find high-IQ men within the group of men with low perception errors for contemporaneous inflation display a large positive and significant association between their inflation expectations and consumption propensities. The size of this association is higher than the size of the baseline association we detected in Table 3. In column (2) of Table 8, the point estimate is positive and economically non-negligible, but we fail to detect a significant association between inflation expectations and consumption propensities for low-IQ men with low perception errors for contemporaneous inflation.

The second channel we consider - costly expectations-formation channel - states low-IQ men might be unable to think in probabilistic terms and about future states of the world (McDowell and Jacobs (2017)). This channel could explain the non-response in the Euler equations only if low-IQ men were sophisticated about their bias.

To assess the relevance of this channel, we exploit the fact the survey asks both numerical and qualitative expectations about inflation and focus on a subsample of men with forecast errors below the median forecast errors for inflation. We define forecast error as the difference between the expected numerical inflation rate over the next 12 months of individual $i$ in months $t$ and the ex-post realized inflation rate in 12 months. Intuitively, 
in this subsample, even low-IQ men are able to think probabilistically and to come up with plausible assessments of future states of the world.

Columns (3) and (4) of Table 8 show only high-IQ men increase their spending propensities when they expect higher inflation. Low-IQ men are still unresponsive, both economically and statistically, even if their expectations about future inflation are close to the ex-post realization.

A third channel, which we label the lack-of-economic-reasoning channel, is low-IQ men might not understand basic economic concepts such as intertemporal optimization. This channel is potentially consistent with all the evidence in the paper and could also rationalize other puzzles in the literature such as the excess sensitivity of consumption to predictable income changes (see, e.g., Parker et al. (2013)). Ilut and Valchev (2017) model agents with limited cognitive knowledge of the optimal action conditional on the economic state and could provide a theoretical foundation for this channel.

A last point to consider is the fact that many economists discard data on household inflation expectations because such data are noisy and sometimes extreme observations occur, which economists take as a sign that those data are unreliable. We agree with the notion that household-level inflation expectations are quite noisy, but disagree with the prescription that because of this noise, economists and policymakers should discard data on household expectations when conducting academic research or designing policies. The very fact that many policies rely on households reacting to higher inflation expectations by increasing their consumption propensities makes understanding which households have plausible inflation expectations and which households understand the theoretical link between inflation expectations and consumption propensities crucial for the effectiveness of economic policies.

\section{Conclusion}

In a representative sample of Finnish men, we find that only men with high cognitive abilities change consumption plans in line with the consumption Euler equation. High-IQ men are also twice as responsive as low-IQ men in their propensity to borrow to interest 
rate changes, and their total debt balances from tax data are also more sensitive to changes in interest rates. Short-term interest rates are the conventional monetary-policy tool of central banks, and consumer credit is a central propagation mechanism of interest rates to the real economy. Our findings suggest that cognitive abilities are a human friction that can limit central banks' ability to stabilize demand both in recessions and expansions. This human friction might inform future theoretical and empirical advances in the recent literature on heterogeneous agents in economics and finance.

The consumption Euler equation is at the core of all dynamic models in macroeconomics and finance. In representative-agent New Keynesian models, conventional and unconventional fiscal policy, as well as monetary policy, typically operates through changes in inflation expectations on households' consumption decisions. The results in this paper show many households might ignore these fundamental assumptions of macroeconomic models and policymaking and therefore not react. Thus, policymakers should design policies in a way that is salient and easy to understand for the whole population. An example of such a salient type of policy is unconventional fiscal policy, such as the pre-announcement of future value-added tax increases (e.g., see D'Acunto, Hoang, and Weber (2018a)). Our results also provide empirical support for recent theoretical advances that deviate from the rational-expectations paradigm, such as Farhi and Werning (2017), Gabaix (2018), Woodford (2018), Garcia-Schmidt and Woodford (2019), and Iovino and Sergeyev (2018).

Our findings also show that the common practice of focusing on financial markets in monetary-policy communication might not be enough. Even if central banks are successful in changing long-term rates by guiding financial markets regarding the future path of short-term interest rates, if a substantial fraction of the population does not react to these changes in rates, the policy might be ineffective. Future research should also study which type of communication tools policymakers can use to reach the overall population instead of only a small fraction of it. Coibion, Gorodnichenko, and Weber (2019) show solely relying on newpspapers and the media might not be sufficient in this respect and that policymakers have to consider novel strategies to communicate with the public.

More broadly, combining economic policies with limited cognitive abilities is likely to 
result in redistributive effects from low-IQ individuals to high-IQ individuals, because only high-IQ individuals adjust their behavior in response to changing economic fundamentals. This redistribution could be interpreted as a form of undue discrimination of low-IQ individuals on the part of policymakers to the extent that cognitive abilities are an innate individual characteristic or are largely determined by early-life environmental factors individuals can barely control. Future empirical and theoretical research should delve into the unintended redistributive effects of economic policies based on individuals' cognitive abilities. 


\section{References}

Agarwal, S., G. Amromin, I. Ben-David, S. Chomsisengphet, T. Piskorski, and A. Seru (2017). Policy intervention in debt renegotiation: Evidence from the home affordable modification program. Journal of Political Economy 125(3), 654-712.

Agarwal, S. and B. Mazumder (2013). Cognitive abilities and household financial decision making. American Economic Journal: Applied Economics 5(1), 193-207.

Aghion, P., U. Akcigit, A. Hyytinen, and O. Toivanen (2017). The social origins of inventors. NBER Working Paper 24110.

Arioli, R., C. Bates, H. Dieden, I. Duca, R. Friz, C. Gayer, G. Kenny, A. Meyler, and I. Pavlova (2017). EU consumers' quantitative inflation perceptions and expectations: An evaluation.

Attanasio, O. P. and G. Weber (1993). Consumption growth, the interest rate and aggregation. The Review of Economic Studies 60(3), 631-649.

Bachmann, R., T. O. Berg, and E. Sims (2015). Inflation expectations and readiness to spend: Cross-sectional evidence. American Economic Journal: Economic Policy 7(1), $1-35$.

Binder, C. (2015). Consumer inflation uncertainty and the macroeconomy: Evidence from a new micro-level measure. Unpublished Manuscript, UC Berkeley.

Burke, M. A. and A. Ozdagli (2014). Household inflation expectations and consumer spending: Evidence from panel data. Unpublished Manuscript, Federal Reserve Bank of Boston 13(25), 1-43.

Christelis, D., D. Georgarakos, T. Jappelli, and M. van Rooij (2016). Trust in the central bank and inflation expectations. Unpublished manuscript, ECB.

Christiano, L., M. Eichenbaum, and S. Rebelo (2011). When is the government spending multiplier large? Journal of Political Economy 119(1), 78-121.

Coibion, O., Y. Gorodnichenko, and S. Kumar (2018). How do firms form their expectations? New survey evidence. American Economic Review 108(9), 2671-2713.

Coibion, O., Y. Gorodnichenko, and M. Weber (2019). Monetary policy communications and their effects on household inflation expectations. Working Paper.

Correia, I., E. Farhi, J. P. Nicolini, and P. Teles (2013). Unconventional fiscal policy at the zero bound. American Economic Review 103(4), 1172-1211.

Crump, R. K., S. Eusepi, A. Tambalotti, and G. Topa (2018). Subjective intertemporal substitution. FRB of New York Staff Report (734).

D'Acunto, F., D. Hoang, M. Paloviita, and M. Weber (2019). IQ, expectations, and choice. Unpublished manuscript, University of Chicago.

D'Acunto, F., D. Hoang, and M. Weber (2018a). The effect of unconventional fiscal policy on consumption expenditure. Working Paper.

D'Acunto, F., D. Hoang, and M. Weber (2018b). Unconventional fiscal policy. American Economic Association Papers and Proceedings 108, 519-23.

D'Acunto, F., U. Malmendier, J. Ospina, and M. Weber (2017). Salient price changes, inflation expectations, and household behavior. Working Paper.

Dal Bo, E., F. Finan, O. Folke, T. Persson, and J. Rickne (2017). Who becomes a politician? Quarterly Journal of Economics 132(4), 1877-1914.

Das, S., C. M. Kuhnen, and S. Nagel (2018). Socioeconomic status and macroeconomic expectations. Unpublished Manuscript, University of Chicago.

Del Negro, M., M. P. Giannoni, and C. Patterson (2015). The forward guidance puzzle. FRB of New York Staff Report (574).

Eggertsson, G. B. (2006). The deflation bias and committing to being irresponsible. Journal of Money, Credit and Banking 38(2), 283-321. 
Eggertsson, G. B. (2011). What fiscal policy is effective at zero interest rates? NBER Macroeconomics Annual 25(1), 59-112.

Eggertsson, G. B. and M. Woodford (2003). The zero bound on interest rates and optimal monetary policy. Brookings Papers on Economic Activity 2003(1), 139-211.

Farhi, E. and I. Werning (2016). Fiscal multipliers: Liquidity traps and currency unions. In Handbook of Macroeconomics, Volume 2, pp. 2417-2492. Elsevier.

Farhi, E. and I. Werning (2017). Monetary policy, bounded rationality, and incomplete markets. Technical report, Unpublished Manuscript, Harvard University.

Gabaix, X. (2018). A behavioral new keynesian model. Unpublished Manuscript, Harvard University.

Garcia-Schmidt, M. and M. Woodford (2019, January). Are low interest rates deflationary? A paradox of perfect-foresight analysis. American Economic Review 109(1), 86-120.

Grinblatt, M., S. Ikäheimo, M. Keloharju, and S. Knüpfer (2015). IQ and mutual fund choice. Management Science 62(4), 924-944.

Grinblatt, M., M. Keloharju, and J. Linnainmaa (2011). IQ and stock market participation. The Journal of Finance 66 (6), 2121-2164.

Grinblatt, M., M. Keloharju, and J. T. Linnainmaa (2012). IQ, trading behavior, and performance. Journal of Financial Economics 104(2), 339-362.

Ichiue, H. and S. Nishiguchi (2015). Inflation expectations and consumer spending at the zero bound: Micro evidence. Economic Inquiry 53(2), 1086-1107.

Ilut, C. and R. Valchev (2017). Economic agents as imperfect problem solvers. Unpublished Manuscript, Boston College.

Iovino, L. and D. Sergeyev (2018). Central bank balance sheet policies without rational expectations. Unpublished Manuscript, Bocconi University.

Jonung, L. (1981). Perceived and expected rates of inflation in Sweden. The American Economic Review 71(5), 961-968.

Kaplan, G., B. Moll, and G. L. Violante (2018). Monetary policy according to HANK. American Economic Review 108(3), 697-743.

Kaplan, G., G. L. Violante, and J. Weidner (2014). The wealthy hand-to-mouth. Brookings Papers on Economic Activity 2014(2), 77-138.

Keys, B. J., D. G. Pope, and J. C. Pope (2016). Failure to refinance. Journal of Financial Economics 122(3), 482-499.

Krugman, P. R., K. M. Dominquez, and K. Rogoff (1998). It's baaack: Japan's slump and the return of the liquidity trap. Brookings Papers on Economic Activity 1998(2), $137-205$.

Malmendier, U. and S. Nagel (2015). Learning from inflation experiences. The Quarterly Journal of Economics 131(1), 53-87.

Mc-Gue, M., T. Bouchard, W. Iacono, and D. Lykken (1993). Behavioral genetics of cognitive ability: A life-span persepctive. In R. Plomin and G. McClearn (Eds.), Nature, Nurture \& Psychology. Washington, D.C.: American Psychological Association.

McDowell, M. and P. Jacobs (2017). Meta-analysis of the effect of natural frequencies on Bayesian reasoning. Psychological bulletin 143(12), 1273-1312.

McKay, A., E. Nakamura, and J. Steinsson (2016). The power of forward guidance revisited. American Economic Review 106(10), 3133-58.

Parker, J. A., N. S. Souleles, D. S. Johnson, and R. McClelland (2013). Consumer spending and the economic stimulus payments of 2008. American Economic Review 103(6), $2530-2553$.

Plomin, R. and F. Spinath (2004). Intelligence: Genetics, Genes, and Genomics. Journal 
of Personality and Social Psychology 86(1), 112-129.

Vellekoop, N. and M. Wiederholt (2017). Inflation expectations and choices of households: Evidence from matched survey and administrative data. Unpublished Manuscript, University of Frankfurt.

Werning, I. (2012). Managing a liquidity trap: Monetary and fiscal policy. Unpublished Manuscript, MIT.

Woodford, M. (2011). Simple analytics of the government expenditure multiplier. American Economic Journal: Macroeconomics 3(1), 1-35.

Woodford, M. (2018). Monetary policy analysis when planning horizons are finite. NBER Macro Annual (forthcoming).

Zeldes, S. P. (1989). Consumption and liquidity constraints: An empirical investigation. The Journal of Political Economy 97(2), 305-346. 
Figure 2: ECB Deposit Facility Rate and Propensity to Borrow by IQ

Panel A. ECB deposit facility rate (2001-2007)

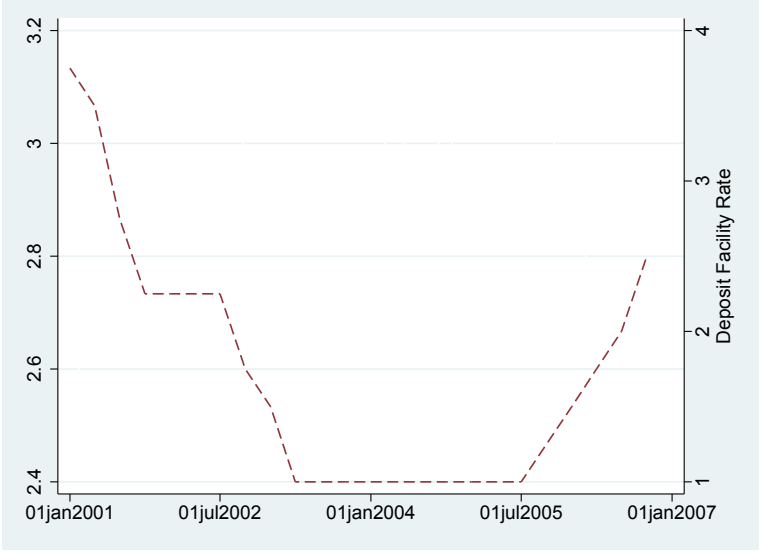

Panel B. Borrowing: High-IQ Men

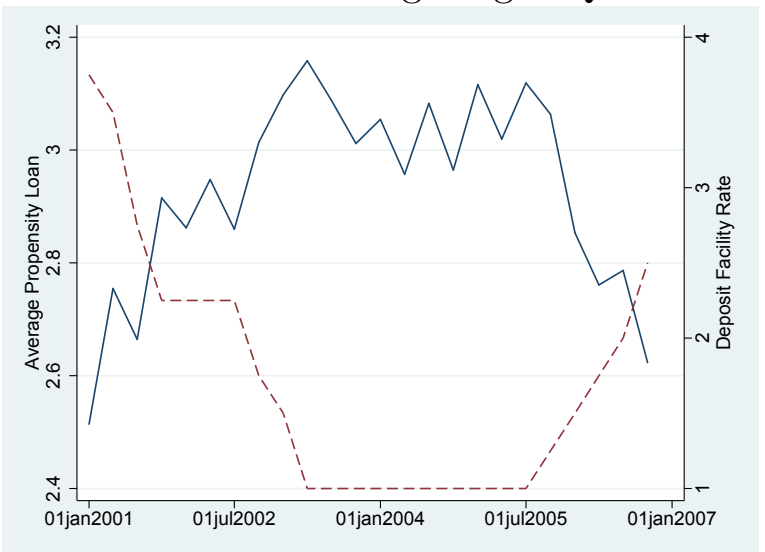

Panel C. Borrowing: Low-IQ

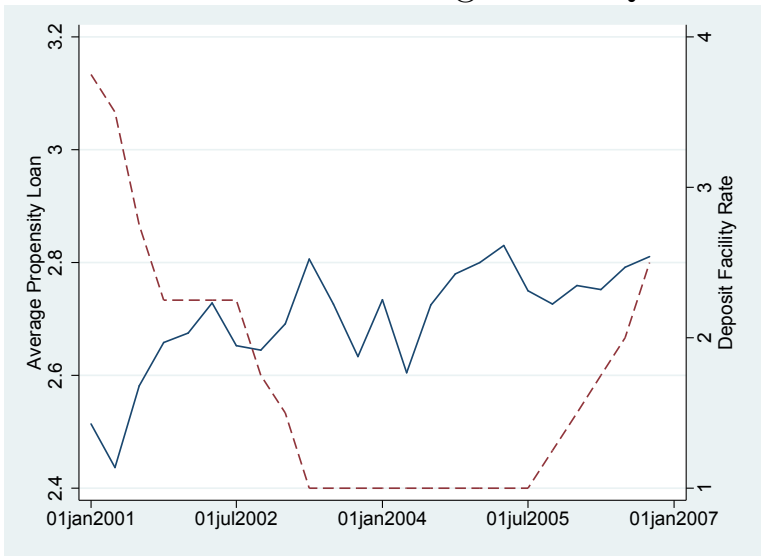

Panel A of this figure plots the beginning of the quarter European Central Bank Deposit Facility Rate from quarter 12001 to quarter 4 of 2006. Panel B and Panel $C$ of this figure plot the cross-sectional mean of whether individuals think it is a good time to take out a loan in Finland by IQ levels. Individuals can answer that now is a "very good time to borrow" (4), a "pretty good time to borrow" (3), a "pretty bad time to borrow" (2), or a "really bad time to borrow" (1) to the question, "If you think about the general economic situation in Finland, then do you think that at this time it is ..." High-IQ men are all men with the highest 3 scores of the 9-point distribution. Low-IQ men are all men with the lowest 3 scores of the 9-point distribution. We use the confidential micro data underlying the official European Commission consumer confidence survey to measure the propensity to take out a loan. IQ is the standardized test score from the military entrance exam test for all men in Finland. IQ obtains integer values between 1 and 9 with 9 being the highest score. The sample period is January 2001 to December 2006. 
Table 1: Descriptive Statistics

This table reports descriptive statistics for the variables we use in the paper. We use the confidential micro data underlying the official European Commission consumer confidence survey to construct these variables. We measure normalized IQ using data from the official military entrance exam in Finland. The sample period is January 2001 to March 2015.

\begin{tabular}{|c|c|c|c|c|c|c|}
\hline Statistic & $\begin{array}{c}\text { Inflation } \\
\text { Perception }\end{array}$ & $\begin{array}{c}\text { Inflation } \\
\text { Expectation }\end{array}$ & Total Debt & $\begin{array}{c}\text { IQ } \\
\text { Dummy }\end{array}$ & Age & Income \\
\hline Nobs & 27,544 & 27,566 & 27,828 & 27,856 & 27,856 & 27,856 \\
\hline Mean & 3.00 & 2.47 & 38,510 & 0 & 31 & 22,516 \\
\hline Std & 4.63 & 3.76 & 53,734 & 0 & 7 & 14,247 \\
\hline p1 & -5.00 & -5.00 & 0 & 0 & 19 & 900 \\
\hline p10 & 0.00 & 0.00 & 0 & 0 & 21 & 6,800 \\
\hline p25 & 0.00 & 0.00 & 0 & 0 & 25 & 13,100 \\
\hline p50 & 2.00 & 2.00 & 14,400 & 0 & 30 & 21,000 \\
\hline p75 & 5.00 & 3.50 & 62,200 & 1 & 36 & 28,850 \\
\hline p90 & 7.00 & 5.00 & 102,200 & 1 & 40 & 38,200 \\
\hline p99 & 20.00 & 15.00 & 242,400 & 1 & 46 & 74,200 \\
\hline \multirow[t]{2}{*}{ Single } & no & $38.75 \%$ & Urban & & no & $64.59 \%$ \\
\hline & yes & $61.25 \%$ & & & yes & $35.41 \%$ \\
\hline \multirow[t]{2}{*}{ Unemployed } & no & $94.11 \%$ & Helsinki & & no & $72.28 \%$ \\
\hline & yes & $5.89 \%$ & & & yes & $27.72 \%$ \\
\hline \multirow[t]{2}{*}{ Kids } & no & $22.43 \%$ & College & & no & $66.06 \%$ \\
\hline & yes & $77.57 \%$ & & & yes & $33.94 \%$ \\
\hline \multirow[t]{3}{*}{ Durables } & Good time & $50.84 \%$ & Loan & & Good time & $70.71 \%$ \\
\hline & Neutral & $28.69 \%$ & & & Bad time & $29.29 \%$ \\
\hline & Bad time & $20.47 \%$ & & & & \\
\hline
\end{tabular}


Table 2: IQ, Income, and Total Debt

This table reports the distribution of $I Q$ in Panel $A$, the household leverage ratio in Panel B, and the share of income in total income in Panel C. IQ is the standardized test score from the military entrance exam test for all men in Finland. IQ obtains integer values between 1 and 9 with 9 being the highest score. Income and debt data come from the registry of Statistics Finland. The sample period is January 2001 to March 2015.

\begin{tabular}{|c|c|c|c|c|c|c|c|c|c|}
\hline & Low IQ & 2 & 3 & 4 & 5 & 6 & 7 & 8 & High IQ \\
\hline & \multicolumn{9}{|c|}{ Panel A. Distribution of Normalized IQ } \\
\hline \multirow[t]{5}{*}{ Nobs } & 1,785 & 3,921 & 4,701 & 10,907 & 13,797 & 11,162 & 7,849 & 4,043 & 3,298 \\
\hline & \multicolumn{9}{|c|}{ Panel B. Total Debt / Taxable Income by IQ } \\
\hline & 0.82 & 0.77 & 0.76 & 0.75 & 0.78 & 0.80 & 0.81 & 0.87 & 0.93 \\
\hline & \multicolumn{9}{|c|}{ Panel C. Income Share by IQ } \\
\hline & $1.86 \%$ & $4.52 \%$ & $6.28 \%$ & $15.38 \%$ & $21.16 \%$ & $17.79 \%$ & $16.11 \%$ & $8.83 \%$ & $8.07 \%$ \\
\hline
\end{tabular}




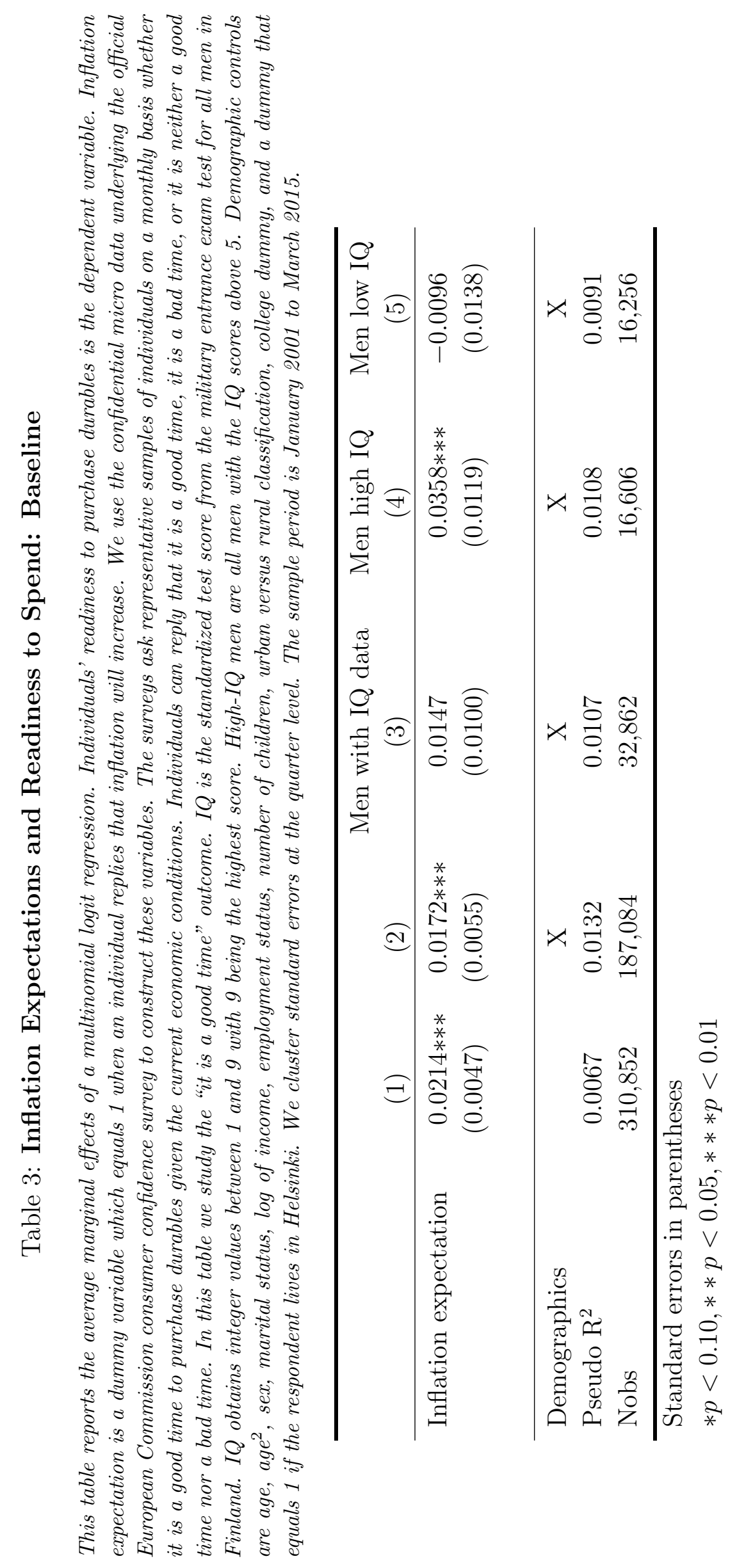




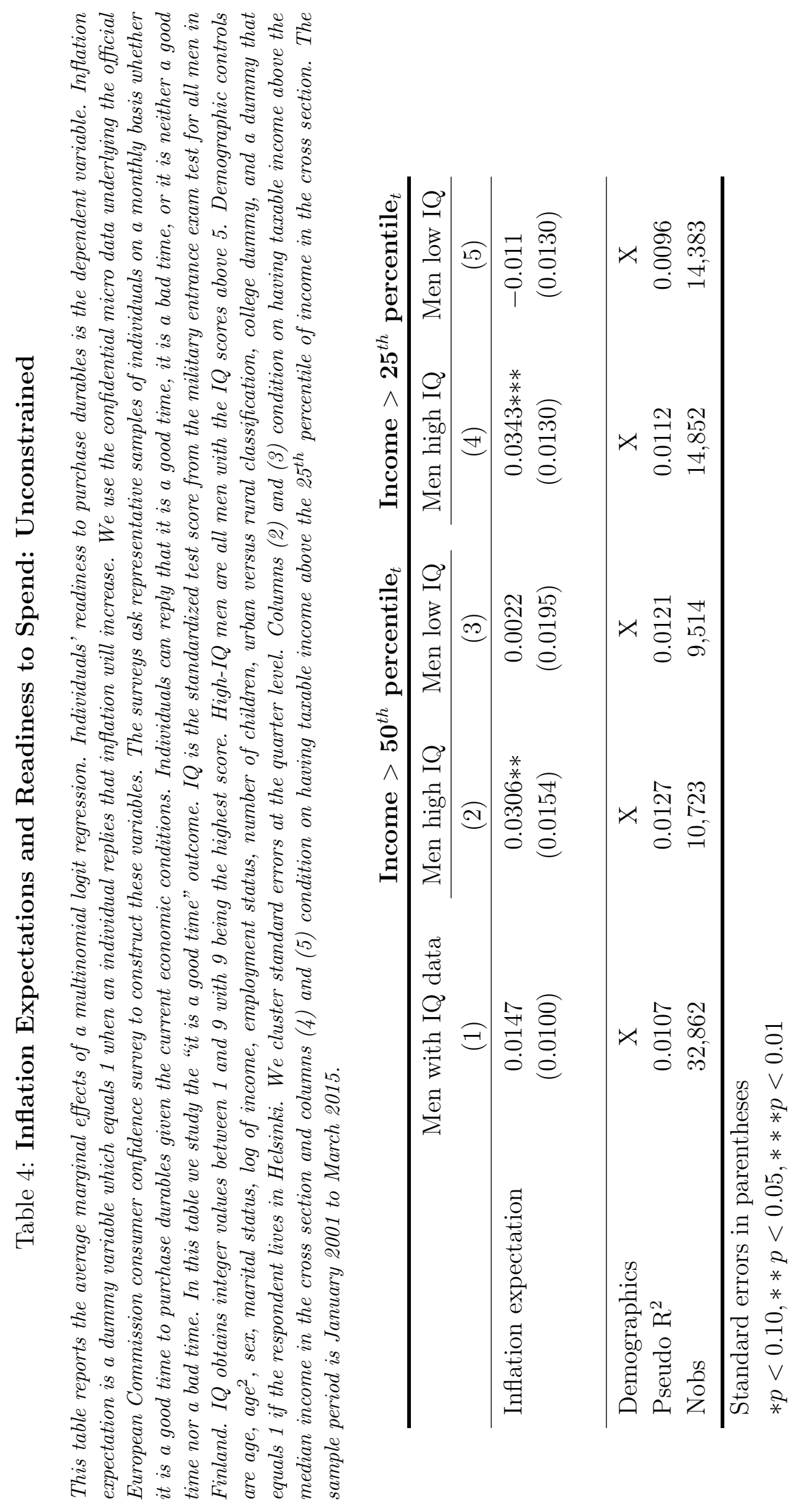




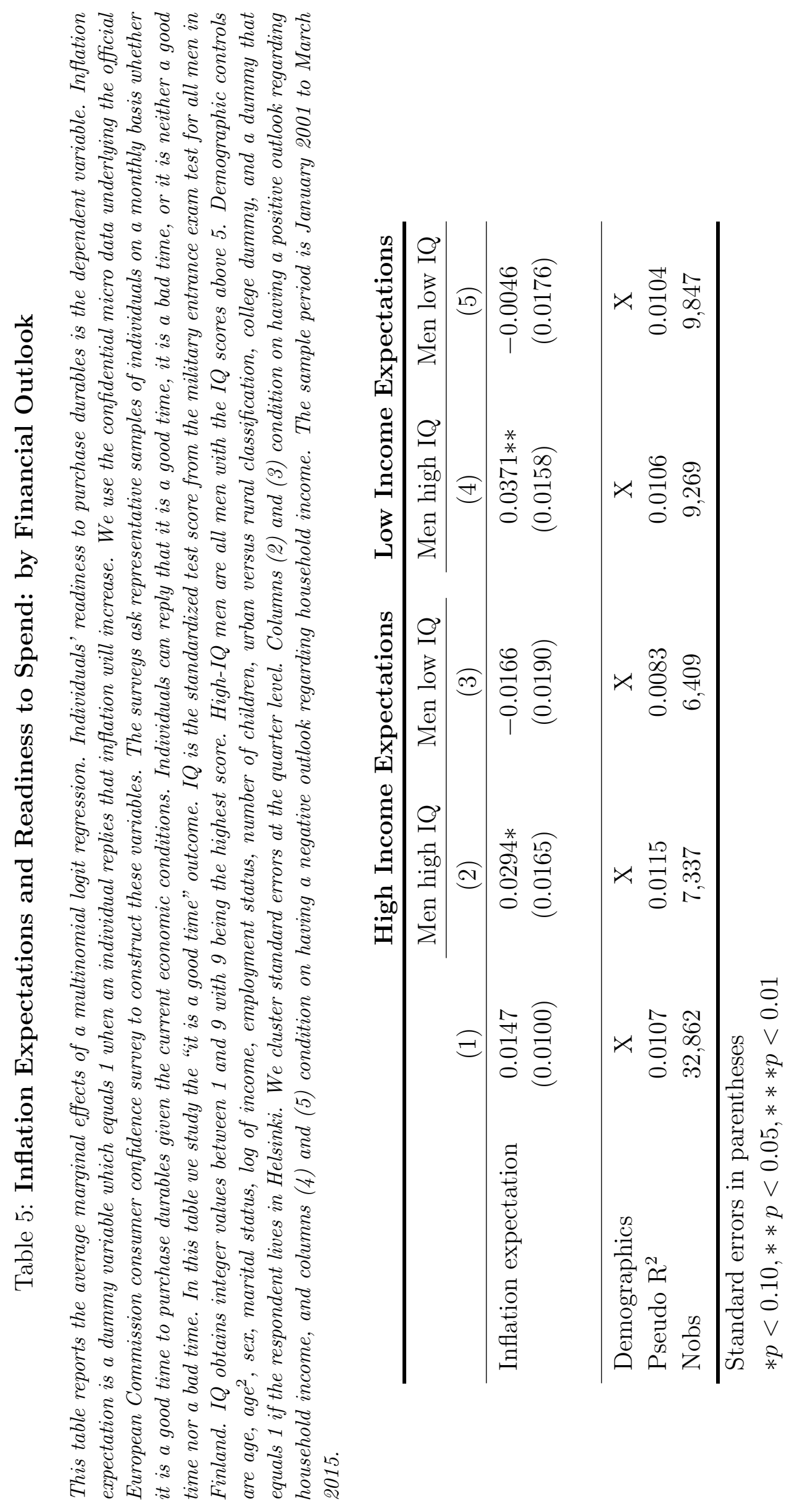




\section{Table 6: Change in the Propensity to Borrow around Interest Rate Changes}

This table reports the coefficient estimates from the following specification:

$$
\text { Loan }_{i, t}=\alpha+\beta I Q D u m m y_{i} \times \text { Post }_{t}+\gamma \text { Post }_{t}+\zeta I Q D u m m y_{i}+X_{i . t}^{\prime} \delta+\epsilon_{i, t},
$$

where Loan $_{i, t}$ is a dummy variable that equals 1 if the respond answers it is a good time to take out a loan, and

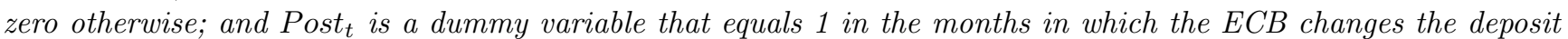
facility rate, and zero in the months before the change. We estimate this specification with a linear probability model $(O L S)$ as well as using non-linear estimators. We use the confidential micro data underlying the official European Commission consumer confidence survey to construct these variables. We measure normalized IQ using data from the official military entrance exam in Finland. IQ is the standardized test score from the military entrance exam test for all men in Finland. IQ obtains integer values between 1 and 9 with 9 being the highest score. IQ dummy equals 1 if normalized $I Q$ is larger than 5. Demographic controls are age, age ${ }^{2}$, sex, marital status, log of income, employment status, number of children, urban versus rural classification, college dummy, and a dummy that equals 1 if the respondent lives in Helsinki. The sample period is January 2001 to December 2006.

\begin{tabular}{|c|c|c|c|c|c|c|}
\hline & $\begin{array}{l}\text { OLS } \\
(1)\end{array}$ & $\begin{array}{l}\text { Probit } \\
(2)\end{array}$ & $\begin{array}{l}\text { Logit } \\
(3)\end{array}$ & $\begin{array}{l}\text { OLS } \\
(4)\end{array}$ & $\begin{array}{l}\text { Probit } \\
(5)\end{array}$ & $\begin{array}{l}\text { Logit } \\
(6)\end{array}$ \\
\hline & \multicolumn{6}{|c|}{ Panel A. Rate Cut: Jan 2001 - June 2003} \\
\hline IQ Dummy & $\begin{array}{c}-0.0278 \\
(0.0293)\end{array}$ & $\begin{array}{c}-0.0241 \\
(0.0274)\end{array}$ & $\begin{array}{c}-0.0248 \\
(0.0282)\end{array}$ & $\begin{array}{c}-0.0482 \\
(0.0325)\end{array}$ & $\begin{array}{c}-0.0445 \\
(0.0295)\end{array}$ & $\begin{array}{r}-0.0448 \\
(0.0308)\end{array}$ \\
\hline Post & $\begin{array}{l}0.0618 * * \\
(0.0218)\end{array}$ & $\begin{array}{r}* 0.0590 *> \\
(0.0222)\end{array}$ & $\begin{array}{c}* 0.0597 * * * \\
(0.0225)\end{array}$ & $\begin{array}{l}0.0648 * * * \\
(0.0251)\end{array}$ & $\begin{array}{c}* 0.0597 * * \\
(0.0258)\end{array}$ & $\begin{array}{l}0.0619 * * \\
(0.0263)\end{array}$ \\
\hline Post $\times$ IQ Dummy & $\begin{array}{l}0.0945 * * \\
(0.0319)\end{array}$ & $\begin{array}{r}* 0.0913 *> \\
(0.0287)\end{array}$ & $\begin{array}{c}* 0.0919 * * * \\
(0.0297)\end{array}$ & $\begin{array}{l}0.0884 * * \\
(0.0352)\end{array}$ & $\begin{array}{l}0.0875 * * * \\
(0.0313)\end{array}$ & $\begin{array}{c}* 0.0883 * * * \\
(0.0326)\end{array}$ \\
\hline Demographics & & & & $\mathrm{X}$ & $\mathrm{X}$ & $\mathrm{X}$ \\
\hline $\mathrm{R}^{2}$ & 0.0121 & 0.0101 & 0.0101 & 0.0509 & 0.0463 & 0.0464 \\
\hline Nobs & 5,850 & 5,850 & 5,850 & 4,070 & 4,070 & 4,070 \\
\hline
\end{tabular}

Panel B. Rate Increase: July 2003 - December 2006

\begin{tabular}{lcccccc}
\hline IQ Dummy & $0.0789 * * *$ & $0.0811 * * *$ & $0.0806 * * *$ & $0.0358 * * *$ & $0.0411 * * *$ & $0.0407 * * *$ \\
& $(0.0108)$ & $(0.0109)$ & $(0.0108)$ & $(0.0124)$ & $(0.0127)$ & $(0.0128)$ \\
Post & 0.0050 & 0.00464 & 0.00471 & $-0.0328 * *$ & $-0.0308 * *$ & $-0.0337 * *$ \\
& $(0.0136)$ & $(0.0130)$ & $(0.0132)$ & $(0.0155)$ & $(0.0154)$ & $(0.0157)$ \\
Post $\times$ IQ Dummy & $-0.0753 * * *-0.0855 * * *$ & $0.0833 * * *$ & $-0.0823 * * *-0.0939 * * *-0.0948 * * *$ \\
& $(0.0202)$ & $(0.0233)$ & $(0.0226)$ & $(0.0218)$ & $(0.0262)$ & $(0.0256)$ \\
& & & & & & \\
\hline Demographics & & & & $\mathrm{X}$ & $\mathrm{X}$ & $\mathrm{X}$ \\
$\mathrm{R}^{2}$ & 0.007 & 0.0067 & 0.0067 & 0.0442 & 0.0465 & 0.0475 \\
Nobs & 8,601 & 8,601 & 8,601 & 5,937 & 5,937 & 5,937 \\
\hline
\end{tabular}

Standard errors in parentheses

$* p<0.10, * * p<0.05, * * * p<0.01$ 


\section{Table 7: Change in Total Outstanding Debt to Interest Rate Changes}

This table reports the coefficient estimates from the following specification:

$$
\Delta \text { debt }_{i, t}=\alpha+\beta I Q D \text { ummy }_{i, t} \times \Delta \text { rates }_{t}+\zeta I Q D u m m y_{i, t}+X_{i . t}^{\prime} \delta+\eta_{t}+\epsilon_{i, t},
$$

where $\Delta$ debt $_{i, t}$ is the annual change in total debt of respondent $i ; \Delta$ rates $t_{t}$ is the annual change in the ECB deposit facility rate; and $X$ is a vector of individual-level controls including age, age ${ }^{2}$, sex, marital status, log of income, employment status, number of children, urban versus rural classification, college dummy, and a dummy that equals 1 if the respondent lives in Helsinki. We use registry data from Statistics Finland to construct these variables. We measure normalized IQ using data from the official military entrance exam in Finland. IQ is the standardized test score from the military entrance exam test for all men in Finland. IQ obtains integer values between 1 and 9 with 9 being the highest score. IQ dummy equals 1 if normalized IQ is larger than 5. The sample period is 2001 to 2011.

\begin{tabular}{lccccc}
\hline & \multicolumn{2}{c}{$2001-2011$} & & \multicolumn{2}{c}{$2001-2007$} \\
\cline { 2 - 3 } \cline { 5 - 6 } IQ Dummy $\times \Delta$ rates & -51.41 & $-56.84 *$ & & $(3)$ & $(4)$ \\
& $(33.23)$ & $(33.29)$ & & $(41.58)$ & $(41.80)$ \\
IQ Dummy & 13.78 & 78.40 & & 45.74 & 59.21 \\
& $(29.90)$ & $(31.32)$ & & $(33.10)$ & $(35.83)$ \\
& & & & & \\
\hline Demographics & & $\mathrm{X}$ & & $\mathrm{X}$ & $\mathrm{X}$ \\
Year FE & 0.002 & 0.008 & & 0.002 & 0.009 \\
$\mathrm{R}^{2}$ & 271,787 & 267,988 & & 154,175 & 152,100 \\
Nobs & & & &
\end{tabular}

Standard errors in parentheses

$* p<0.10, * * p<0.05, * * * p<0.01$ 


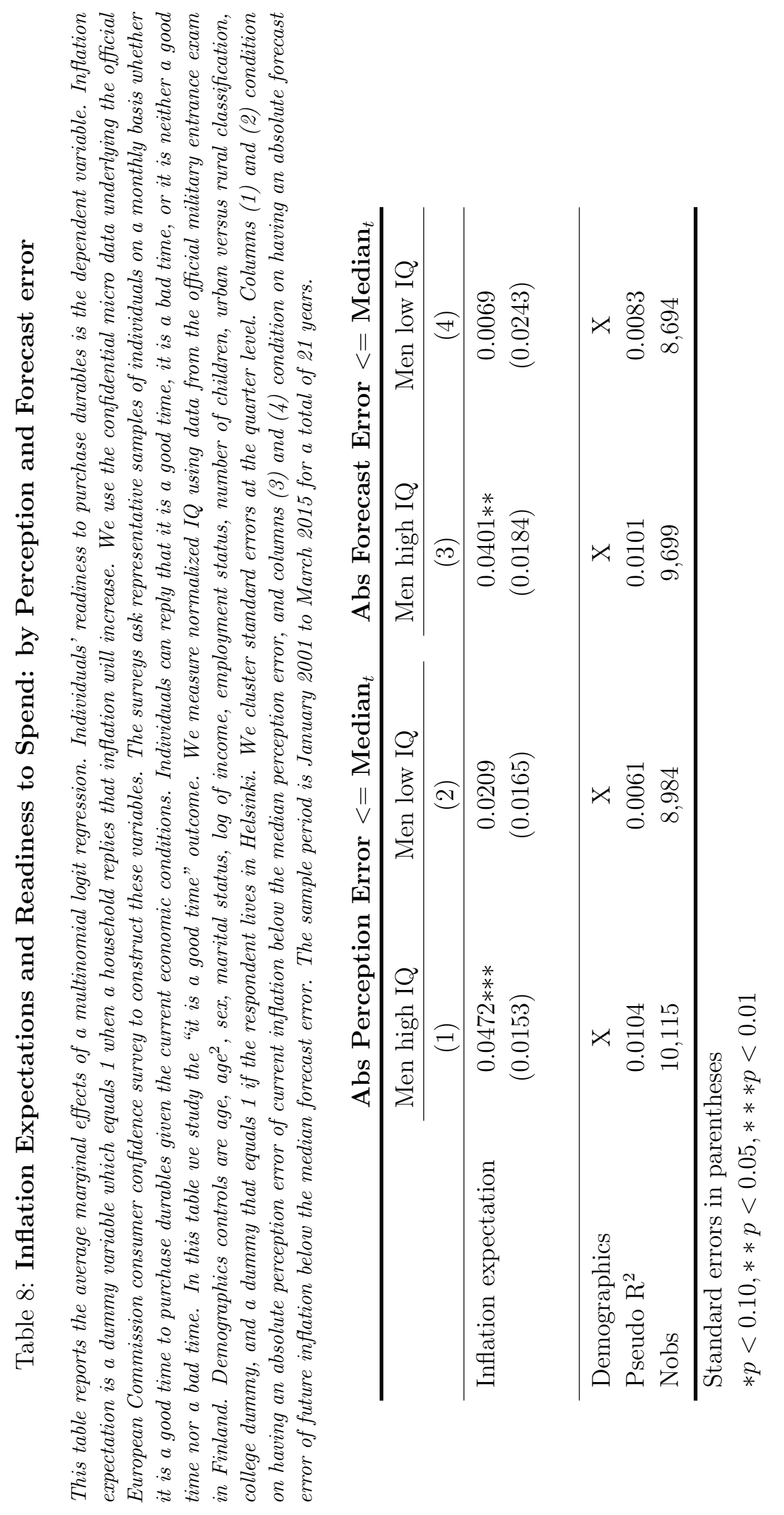




\section{Online Appendix: \\ Human Frictions to the Transmission of Economic Policy}

Francesco D'Acunto, Daniel Hoang, Maritta Paloviita, and Michael Weber

Not for Publication 
Table A.1: Change in the Propensity to Take out Loan to Rate changes: unconstrained

This table reports the coefficient estimates from the following specification:

$$
\text { Loan }_{i, t}=\alpha+\beta I Q \text { Dummy }_{i} \times \text { Post }_{t}+\gamma \text { Post }_{t}+\zeta I Q D u m m y_{i}+X_{i . t}^{\prime} \delta+\epsilon_{i, t},
$$

where Loan $_{i, t}$ is a dummy variable that equals 1 if the respond answers it is a good time to take out a loan, and zero otherwise; and Post $t_{t}$ is a dummy variable that equals 1 in the months in which the ECB changes the deposit facility rate, and zero in the months before the change. We estimate this specification with a linear probability model $(O L S)$ as well as using non-linear estimators. We use the confidential micro data underlying the official European Commission consumer confidence survey to construct these variables. We measure normalized IQ using data from the official military entrance exam in Finland. IQ is the standardized test score from the military entrance exam test for all men in Finland. IQ obtains integer values between 1 and 9 with 9 being the highest score. IQ dummy equals 1 if normalized IQ is larger than 5. Demographic controls are age, age $e^{2}$, sex, marital status, log of income, employment status, number of children, urban versus rural classification, college dummy, and a dummy that equals 1 if the respondent lives in Helsinki. The sample period is January 2001 to December 2006.

\begin{tabular}{|c|c|c|c|c|c|c|}
\hline & $\begin{array}{l}\text { OLS } \\
(1)\end{array}$ & $\begin{array}{c}\text { Probit } \\
(2)\end{array}$ & $\begin{array}{c}\text { Logit } \\
(3)\end{array}$ & $\begin{array}{c}\text { OLS } \\
(4)\end{array}$ & $\begin{array}{c}\text { Probit } \\
(5)\end{array}$ & $\begin{array}{c}\text { Logit } \\
(6)\end{array}$ \\
\hline & \multicolumn{6}{|c|}{ Panel A. Rate Cut: Jan 2001 - June 2003} \\
\hline IQ Dummy & $\begin{array}{c}0.0005 \\
(0.0319)\end{array}$ & $\begin{array}{c}0.0004 \\
(0.0284)\end{array}$ & $\begin{array}{c}0.0004 \\
(0.0299)\end{array}$ & $\begin{array}{r}-0.0361 \\
(0.0335)\end{array}$ & $\begin{array}{r}-0.0339 \\
(0.0299)\end{array}$ & $\begin{array}{r}-0.0342 \\
(0.0315)\end{array}$ \\
\hline Post & $\begin{array}{r}0.1002 * \\
(0.0238)\end{array}$ & $\begin{array}{c}0.0936 * * \\
(0.0250)\end{array}$ & $\begin{array}{l}=0.0951 * * * \\
(0.0253)\end{array}$ & $\begin{array}{l}0.0753 * * \\
(0.0257)\end{array}$ & $\begin{array}{c}* 0.0685 * * * \\
(0.0265)\end{array}$ & $\begin{array}{c}* 0.0708 * * * \\
(0.0271)\end{array}$ \\
\hline Post $\times$ IQ Dummy & $\begin{array}{r}0.0663 * \\
(0.0348)\end{array}$ & $\begin{array}{c}0.0693 * * \\
(0.0305)\end{array}$ & $\begin{array}{l}0.0688 * * \\
(0.0319)\end{array}$ & $\begin{array}{l}0.0789 * * \\
(0.0361)\end{array}$ & $\begin{array}{c}0.0805 * * \\
(0.0317)\end{array}$ & $\begin{array}{c}0.0808 * * \\
(0.0333)\end{array}$ \\
\hline Demographics & & & & $\mathrm{X}$ & $\mathrm{X}$ & $\mathrm{X}$ \\
\hline $\mathrm{R}^{2}$ & 0.0179 & 0.0158 & 0.0158 & 0.0468 & 0.0439 & 0.0437 \\
\hline Nobs & 4,422 & 4,422 & 4,422 & 3,804 & 3,804 & 3,804 \\
\hline
\end{tabular}

Panel B. Rate Increase: July 2003 - December 2006

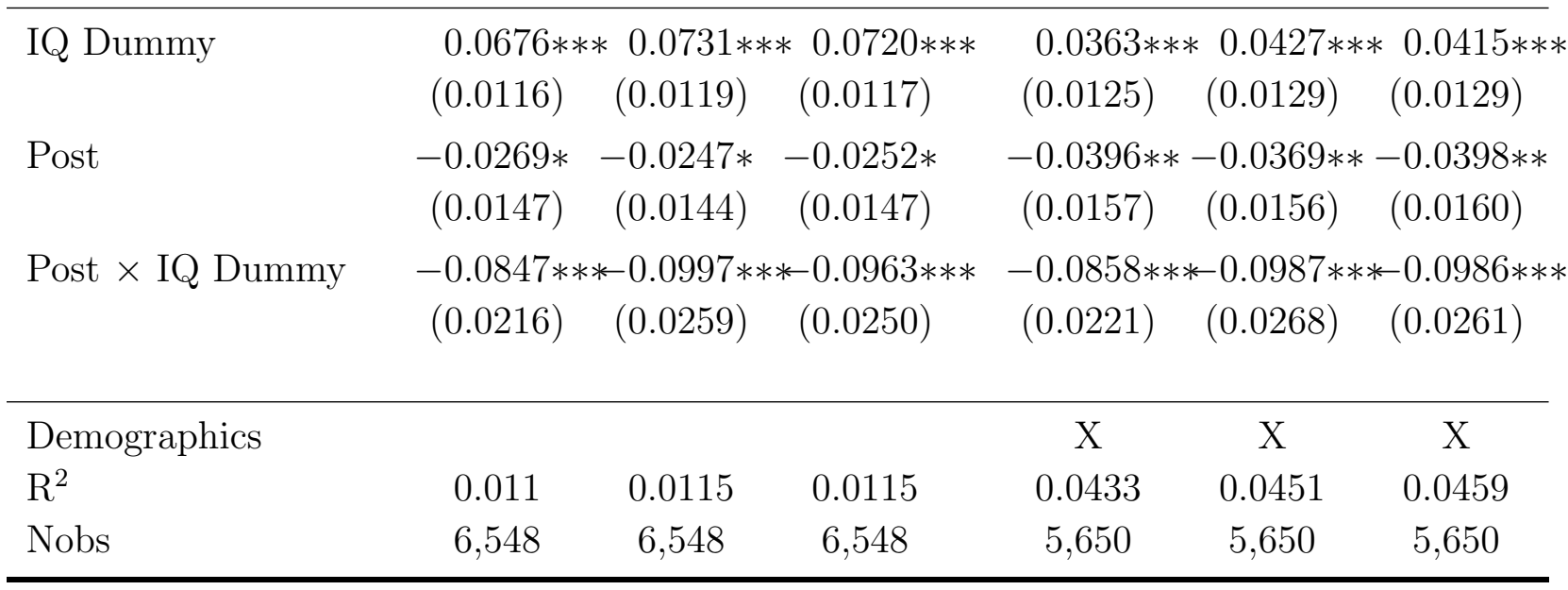

Statistics in parentheses

$* p<0.10, * * p<0.05, * * * p<0.01$ 


\section{Working Paper Series in Economics}

recent issues

No. 128 Francesco D'Acunto, Daniel Hoang, Maritta Paloviita and Michael Weber: Human frictions in the transmission of economic policy, January 2019

No. 127 Francesco D'Acunto, Daniel Hoang, Maritta Paloviita and Michael Weber: IQ, expectations, and choice, January 2019

No. 126 Francesco D'Acunto, Daniel Hoang, Maritta Paloviita and Michael Weber: Cognitive abilities and inflation expectations, January 2019

No. 125 Rebekka Buse, Melanie Schienle and Jörg Urban: Effectiveness of policy and regulation in European sovereign credit risk markets - A network analysis, January 2019

No. 124 Chong Liang and Melanie Schienle: Determination of vector error correction models in high dimensions, January 2019

No. 123 Rebekka Buse and Melanie Schienle: Measuring connectedness of euro area sovereign risk, January 2019

No. 122 Carsten Bormann and Melanie Schienle: Detecting structural differences in tail dependence of financial time series, January 2019

No. 121 Christian Conrad and Melanie Schienle: Testing for an omitted multiplicative long-term component in GARCH models, January 2019

No. 120 Marta Serra-Garcia and Nora Szech: The (in)elasticity of moral ignorance, December 2018

No. 119 Thomas Mariotti, Nikolaus Schweizer, Nora Szech and Jonas von Wangenheim: Information nudges and self-control, November 2018

No. 118 Andranik S. Tangian: Methodological notes on composite indicators for monitoring working conditions, October 2018 